\title{
Ozone Risk Assessment Utilities (ORAMUS) User's Manual and Tutorial: Volume 2, Chronic Health Endpoints
}

Decision and Information Sciences Division

Argonne National Laboratory

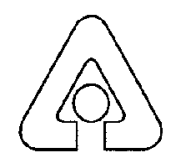

Operated by The University of Chicago, under Contract W-31-109-Eng-38, for the United States Department of Energy 


\section{Argonne National Laboratory}

Argonne National Laboratory, with facilities in the states of Illinois and Idaho, is owned by the United States Government, and operated by the University of Chicago under the provisions of a contract with the Department of Energy.

This technical report is a product of Argonne's Decision and Information Sciences Division. For information on the division's scientific and engineering activities, contact:

Director, Decision and Information

Sciences Division

Argonne National Laboratory

Argonne, Illinois 60439-4832

Telephone (630) 252-5464

Home page: http://www.dis.anl.gov/

Publishing support services were provided by Argonne's Information and Publishing Division (for more information, see IPD's home page: http://www.ipd.anl.gov/).

\section{Disclaimer}

This report was prepared as an account of work sponsored by an agency of the United States Government. Neither the United States Government nor any agency thereof, nor any of their employees, makes any warranty, express or implied, or assumes any legal liability or responsibility for the accuracy, completeness, or usefulness of any information, apparatus, product, or process disclosed, or represents that its use would not infringe privately owned rights. Reference herein to any specific commercial product, process, or service by trade name, trademark, manufacturer, or otherwise, does not necessarily constitute or imply its endorsement, recommendation, or favoring by the United States Government or any agency thereof. The views and opinions of authors expressed herein do not necessarily state or reflect those of the United States Government or any agency thereof.

Reproduced directly from the best available copy.

Available to DOE and DOE contractors from the Office of Scientific and Technical Information, P.O. Box 62, Oak Ridge, TN 37831; prices available from (423) 576-8401.

Available to the public from the National Technical Information Service, U.S. Department of Commerce, 5285 Port Royal Road, Springfield, VA 22161. 


\section{Ozone Risk Assessment Utilities (ORAMUS) User's Manual and Tutorial: Volume 2, Chronic Health Endpoints}

by R.G. Whitfield, M.J. Jusko, and M.A. Clemmons*

Decision and Information Sciences Division,

Argonne National Laboratory, 9700 South Cass Avenue, Argonne, Illinois 60439

December 1998

Work sponsored by U.S. Environmental Protection Agency,

Office of Air Quality Planning and Standards

*Clemmons is affiliated with Argonne's Information and Publishing Division. 
This report is printed on recycled paper. 
FOREWORD $\ldots \ldots \ldots \ldots \ldots \ldots \ldots \ldots \ldots \ldots \ldots$ vii

DISCLAIMER $\ldots \ldots \ldots \ldots \ldots \ldots \ldots \ldots \ldots \ldots \ldots \ldots \ldots \ldots \ldots$ viii

ACKNOWLEDGMENTS $\ldots \ldots \ldots \ldots \ldots \ldots \ldots \ldots$ ix

ABSTRACT $\ldots \ldots \ldots \ldots \ldots \ldots \ldots \ldots \ldots \ldots \ldots \ldots \ldots \ldots \ldots \ldots$

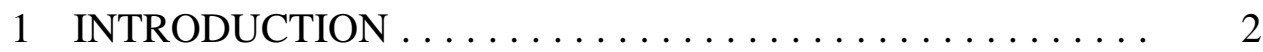

2 INSTALLING THE ORAMUS SYSTEM . . . . . . . . . . 8

Windows 3.1 and Windows 95 Installation $\ldots \ldots \ldots \ldots \ldots$

DOS Installation $\ldots \ldots \ldots \ldots \ldots \ldots \ldots \ldots$

3 GETTING TO KNOW THE ORAMUS SYSTEM $\ldots . . \ldots \ldots .11$

4 HEADCOUNT RISKS FOR CHRONIC ENDPOINTS . . . . . . 17

Choosing between Acute and Chronic Health Endpoints . . . . 17

Setup for Computing or Viewing Selected Risk

Results for Chronic Health Endpoints . . . . . . . . . . . . 18

Specifying Active Air Quality Scenarios . . . . . . . . . . . . . 19

Setup for Computing Selected Risk Results

for Chronic Health Endpoints . . . . . . . . . . . 21

Directory Structure and File Naming Conventions . . . . . . . 22

Viewing Risk Results as Probability Distributions . . . . . . . . 23

Representative Distributions and Vector

Graphics Images . . . . . . . . . . . . . . . . . . 26

Differences between the Reference Scenario and

Other Scenarios . . . . . . . . . . . . . . . . . . . . 28

Viewing Risk Results in Box Plot Format . . . . . . . . . . 28

Creating a Vector Graphics Image File . . . . . . . . . . . 31 


\section{CONTENTS (Cont.)}

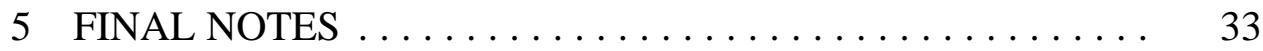

An Extra Utility — LOOKERF.EXE . . . . . . . . . . . 33

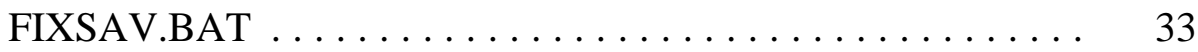

GEN.EXE — A Vector Graphics Generator . . . . . . . . . 34

Installation and Use of the ORAMUS Source Code . . . . . . 35

Sample Output Files . . . . . . . . . . . . . . . . . 36

Running ORAMUS Executables Directly in DOS ......... 36

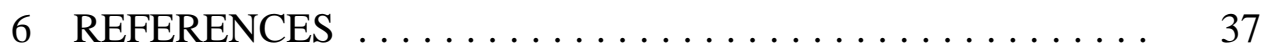

APPENDIX A: Formats of Principal Chronic Input and

Output Files . . . . . . . . . . . . . . . . . 39

APPENDIX B: Information about Health Endpoints and Air Quality Scenarios Used in ORAMUS . . . . . . . . . . 45

\section{FORMS AND EXAMPLES}

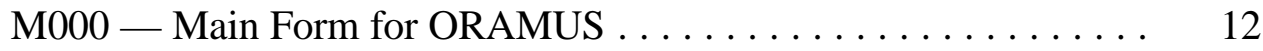

Keystrokes for Moving around in Forms . . . . . . . . . . . 14

Screen Colors for Forms $\ldots \ldots \ldots \ldots \ldots \ldots \ldots \ldots$

Example of Help Documentation for ORAMUS Forms . . . . . . . 14

H000 — Main Form for Headcount Risk Models . . . . . . . . . . 16

C000 - Setup Form for Computing or Viewing

Risk Results for Chronic Health Endpoints . . . . . . . . . . . . . 19

PickAQS — Form for Selecting Active Air Quality Scenarios . . . . 20

Setup for Computing Selected Risk Results

for Chronic Health Endpoints . . . . . . . . . . . . . 22 


\section{FORMS AND EXAMPLES (Cont.)}

A Set of 10 Risk Distributions for Each of 2 Air

Quality Scenarios ........................ 24

P502 — Form for Controlling Graph Properties . . . . . . . . . . 25

P502A - Form for Controlling Properties of a WordPerfect

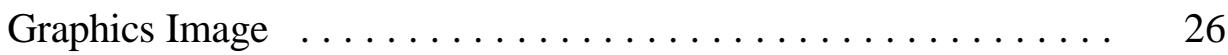

Example of a WordPerfect Graphics Image . . . . . . . . . 27

Differences between the Reference Representative

Distribution and Other Distributions $\ldots \ldots \ldots \ldots 28$

GENBOX1 - Form for Specifying the Contents

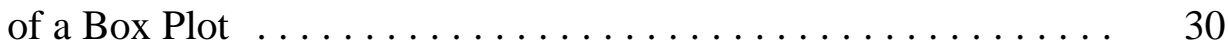

GENBOX2 - Form for Specifying the Appearance of the Box Plot ..................... 31

Vector Graphics Image of the Box Plot Format for Chronic Risk Results . . . . . . . . . . . . . . . . . . . . . . . . . 31

\section{TABLES}

1 Approximate Disk Space Required for Installing ORAMUS Compared with Cluster Size .......... 8

2 Schematic for ORAMUS $\ldots \ldots \ldots \ldots \ldots \ldots \ldots \ldots$

3 File Naming Conventions for Chronic Health Endpoints . . . . 23

A.1 Exposure Probability File for Headcount Risk Endpoints: Los Angeles, Children, 8-hour Exposures,

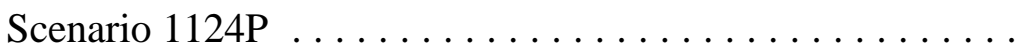




\section{TABLES (Cont.)}

A.2 Exposure-Response Relationship File for a Chronic Health Endpoint: Expert A, Mild Lesions, Los Angeles and New York City, Children and Workers, One Ozone Season . . . . . . . . . . . . . . . . . . 42

A.3 Risk Results File for a Chronic Health Endpoint: Expert A, Mild Lesions, Los Angeles, Children, One Ozone Season, Scenario $1124 \mathrm{P} \ldots \ldots \ldots \ldots \ldots \ldots \ldots \ldots . \ldots \ldots$

B.1 Air Quality Scenarios Available for Chronic Risk Assessments ....................... 46 
The ORAMUS (Ozone Risk AssessMent UtilitieS) code and this documentation were prepared for the U.S. Environmental Protection Agency (EPA) under a contract with the U.S. Department of Energy (DOE). Any distribution of the software package, or other data therein, outside of EPA or DOE offices or contractors, unless otherwise specifically provided for, is prohibited without the approval of the Energy Science and Technology Software Center. Requests from outside DOE for DOEdeveloped computer software should be directed to the Energy Science and Technology Software Center, P.O. Box 1020, Oak Ridge, TN 37831-1020; phone 423-576-2606. 
This work was funded through Interagency Agreement DW89935085-01-3 between the U.S. Environmental Protection Agency (EPA) and the U.S. Department of Energy (DOE). Any opinions, findings, conclusions, or recommendations are those of the authors and do not necessarily reflect the views of reviewers, people named in the acknowledgments, the EPA, the DOE, or Argonne National Laboratory. Comments concerning the report should be addressed to Harvey Richmond, U.S. Environmental Protection Agency, Office of Air Quality Planning and Standards, MD-15, Research Triangle Park, NC 27711. 


\section{ACKNOWLEDGMENTS}

The ORAMUS (Ozone Risk AssessMent UtilitieS) software package is a result of the support and encouragement of Harvey M. Richmond and Karen Martin from the U.S. Environmental Protection Agency, Office of Air Quality Planning and Standards. Additional software tools (which are not a part of ORAMUS) for calculating benchmark risk results were developed by Dr. William F. Biller under U.S. Environmental Protection Agency contract number 68D30092.

The authors also extend their appreciation to the Information and Publishing Division (IPD) at Argonne National Laboratory.

Don Timmerman (Technical Communication Services) assisted in validating ORAMUS. IPD's Document Processing and Control Center prepared the final manuscript. 


\title{
OZONE RISK ASSESSMENT UTILITIES (ORAMUS) USER'S MANUAL AND TUTORIAL: VOLUME 2, CHRONIC HEALTH ENDPOINTS
}

\author{
R.G. Whitfield, M.J. Jusko, and M.A. Clemmons
}

\section{ABSTRACT}

The primary purpose of this manual is to provide instructions on how to install and use the ORAMUS (Ozone Risk AssessMent UtilitieS) software.

ORAMUS is a DOS-based software system that allows you to calculate and view risk estimates for health effects attributable to short- and longterm exposure to tropospheric ozone. The system combines exposure estimates with exposure-response relationships and then calculates and displays estimates of the overall risk in the form of probability distributions. ORAMUS allows you to select from three basic models: headcount risk, benchmark risk, and hospital admissions. It calculates a wide range of risk results for 27 air quality scenarios, 9 urban areas, 33 acute health endpoints, 4 chronic health endpoints, and 3 populations of interest. This manual is a tutorial designed to guide you through a series of steps that will familiarize you with the features of the system. The manual consists of two volumes. Volume 1 addresses acute health endpoints, and Volume 2 covers chronic health endpoints. Acute results were used during the National Ambient Air Quality Standards review process for ozone. Chronic results were not used. 


\section{INTRODUCTION}

The primary purpose of this manual is to provide instructions on the installation and use of the ORAMUS (Ozone Risk AssessMent UtilitieS) software. The manual is a tutorial; that is, you will be instructed to perform steps designed to help you become familiar with the program's functions. You can obtain more details about the format, interpretation of the results, and types of figures that can be created in ORAMUS by examining detailed reports by Whitfield (1997a,b) and Whitfield et al. (1996). For more details concerning the approach used to estimate risks for chronic health effects associated with ozone, see Whitfield et al. (1991) and Winkler et al. (1995). Some of the basic capabilities of ORAMUS are described in this section. If you are already familiar with these capabilities, you can proceed directly to Section 2, which contains the instructions for installing ORAMUS on your IBM-compatible personal computer (PC).

ORAMUS produces risk results by combining exposure-response relationships with air quality and exposure estimates for alternative National Ambient Air Quality Standards (NAAQS) for ozone. The risks are described in terms of three basic types of health endpoints:

$<$ Hospital admissions of asthmatics or patients with various respiratory problems;

$<$ Acute health effects, such as coughing, chest pain when taking a deep breath, and decreased forced expiratory volume; and

$<$ Chronic health effects, such as the formation of lesions in the centriacinar region of the human lung.

Refer to Volume 1 for instructions on using the acute risk assessment capabilities of ORAMUS.

Two fundamental types of risk measures are used:

$<$ Headcount risk: Headcount risk refers to the number of persons or the number of times individuals from a specific population experience a particular "event," that is, a hospital admission, cough, chest pain, or decreased lung function. Included in the headcount risk measure is the percentage of 
possible events estimated to occur. This measure of risk combines exposure-response relationships with exposure estimates about various populations as they go about their daily activities. The hospital admissions measure is a type of headcount risk.

To obtain headcount risk distributions, ORAMUS combines probabilistic exposure-response relationships with exposure estimates. Acute relationships are derived from various sources, primarily experimental and observational data for acute effects in humans. Chronic relationships are the result of expert judgment. Exposure estimates, which are also probabilistic, were obtained from the recently developed probabilistic version of the NAAQS exposure model for ozone $\left(\mathrm{pNEM} / \mathrm{O}_{3}\right)$. The output from $\mathrm{pNEM} / \mathrm{O}_{3}$ includes results for 10 separate runs of the model, which allow you to gain insights about the effects of run-to-run variations on risk output. Precursors to $\mathrm{pNEM} / \mathrm{O}_{3}$ have been described by Paul et al. (1986), Johnson et al. (1990), McCurdy et al. (1991), and McCurdy (1994). Exposure estimates used in ORAMUS have been developed and are described by Johnson (1997) and Johnson et al. (1996a-c, 1997).

$<$ Benchmark risk: Benchmark risk is a measure of the hazard posed by elevated ambient ozone levels. It is calculated by assuming that all members of the at-risk population are exposed outdoors under identical exposure conditions. In contrast to the headcount risk, benchmark risk focuses on the probability, or risk, of unhealthful air.

Benchmark response $r$ is the fraction of the population that may experience a specific health effect when exposed to ozone. Benchmark risk is the probability that the benchmark response is $\$ r, n$ or more times in a specified period (one ozone season) at some location within a geographic region, given a particular air quality condition (e.g., that Scenario 1112 [see description on page 5] is just attained). The software accommodates $r$ values of $0.01,0.05$, and 0.1 (sometimes referred to as 0.01 , 0.05 , and 0.1 benchmarks or $1 \%, 5 \%$, and $10 \%$ benchmarks, respectively). 
Headcount risks are represented by probability distributions (also called risk distributions) over a variety of risk measures. An example of a risk measure is the number of children who spend considerable time outdoors (outdoor children) and may develop centriacinar lesions that can be attributed to exposure to tropospheric ozone during one ozone season in Los Angeles. Probability distributions generally are needed to represent the risks fairly because of the considerable uncertainty regarding the amount of exposure that individuals and populations receive and the degree to which they experience various health endpoints at specific exposure levels.

The hospital admissions model has elements of both the benchmark and the headcount risk models. It uses air quality data, as does the benchmark risk model, and a concentration-response relationship that resembles the exposure-response relationships used in the headcount risk model. The hospital admissions model assumes a linear relationship between hospital admissions (the response) and the previous day's highest hourly average ozone concentration, as measured at a fixed-site monitor.

Risk measures are composed of several factors:

$<$ Population of interest, such as outdoor children, outdoor workers, asthmatics, and the general population;

$<$ Type of effect, such as hospital admission, coughing, chest pain, decreased lung function, and formation of lesions in the human lung;

$<$ Area of residence, for example, any of nine urban areas;

$<$ Length of exposure (1 or 8 hours for acute endpoints; 1 or 10 ozone seasons for chronic endpoints);

$<$ Numbers or percentages of children or workers; and

$<$ Method of counting multiple exposures or occurrences of an effect experienced by an individual. 
Risk results also depend on alternative NAAQS, which have several components:

$<$ Averaging time (1- or 8-hour daily maximum average);

$<$ Form of the standard (i.e., the expected exceedances in one year or $n$ 'th highest average daily maximum); and

$<$ Allowed concentration $(0.07,0.08,0.09,0.10$, or 0.12 part per million $[\mathrm{ppm}]$ of ozone).

Of the many possible combinations of these components, ORAMUS can analyze the following 26 NAAQS, each referenced by a scenario number based on components of that specific scenario (the derivation of the number is indicated in bold for the first scenario only; the scenario reference in parentheses gives the standard EPA designation):

< Scenario 1112 (1H1EX-0.12): 1-hour daily maximum average, 1 expected exceedance, $0.12 \mathrm{ppm}$ of ozone, which was the previous ozone 1-hour standard;

< Scenario 1110 (1H1EX-0.10): 1-hour daily maximum average, 1 expected exceedance, $0.10 \mathrm{ppm}$ of ozone;

< Scenario 8110 (8H1EX-0.10): 8-hour daily maximum average, 1 expected exceedance, $0.10 \mathrm{ppm}$ of ozone;

< Scenario 8109 (8H1EX-0.09): 8-hour daily maximum average, 1 expected exceedance, $0.09 \mathrm{ppm}$ of ozone;

< Scenario 8108 (8H1EX-0.08): 8-hour daily maximum average, 1 expected exceedance, $0.08 \mathrm{ppm}$ of ozone;

< Scenario 8107 (8H1EX-0.07): 8-hour daily maximum average, 1 expected exceedance, $0.07 \mathrm{ppm}$ of ozone;

< Scenario 8509 (8H5EX-0.09): 8-hour daily maximum average, 5 expected exceedances, $0.09 \mathrm{ppm}$ of ozone;

$<$ Scenario 8508 (8H5EX-0.08): 8-hour daily maximum average, 5 expected exceedances, $0.08 \mathrm{ppm}$ of ozone; 
< Scenario 1124* (1H1EX-0.124): 1-hour averaging time, 1 expected exceedance, $0.124 \mathrm{ppm}$ of ozone, which portrays the previous 1-hour standard and reflects the rounding convention used to judge attainment of the standard;

< Scenario 8394* (8HA3H-0.094): 8-hour averaging time, third highest daily maximum, 0.094 ppm of ozone;

< Scenario 8784* (8HA7H-0.084): 8-hour averaging time, seventh highest average daily maximum of $0.084 \mathrm{ppm}$ of ozone;

< Scenario 8584* (8HA5H-0.084): 8-hour averaging time, fifth highest average daily maximum of $0.084 \mathrm{ppm}$ of ozone;

< Scenario 8384* (8HA3H-0.084): 8-hour averaging time, third highest average daily maximum of $0.084 \mathrm{ppm}$ of ozone;

< Scenario 8294 (8HA2H-0.094): 8-hour averaging time, second highest average daily maximum of $0.094 \mathrm{ppm}$ of ozone;

< Scenario 8284 (8HA2H-0.084): 8-hour averaging time, second highest average daily maximum of $0.084 \mathrm{ppm}$ of ozone; and

< Scenario 8380 (8HA3H-0.080): 8-hour averaging time, third highest average daily maximum of $0.080 \mathrm{ppm}$ of ozone.

Note: An asterisk indicates a scenario that has three sets of air quality estimates. These sets include estimates for each of three air quality adjustment procedures: proportional (used for the first eight scenarios), Weibull, and quadratic. Johnson et al. (1997) provides additional information on these adjustment procedures.

A twenty-seventh scenario, which represents existing air quality, is referred to as the "As-Is" scenario. Data for the As-Is scenario are from either 1990 or 1991 for each urban area.

In all cases, the average level is a "daily maximum" value, that is, the highest daily 1- or 8-hour average for each day of the ozone season. Although the 1- or 8-hour average ozone concentration can exceed a specific ozone level two or more times in a given day, only one exceedance will "count" for a specific day and year. 
While the previous 1-hour standard (or any new standard) actually addresses a three-year period for determining compliance, the results are based, with one exception, on only one ozone season. (The exception is the health endpoint for the formation of lesions after exposure for 10 ozone seasons.) Since air quality data were adjusted to simulate "just attaining" a given standard and a single ozone season, actual exposures and risks can be either lower or higher in different years during the period used to judge compliance with a standard. 
The ORAMUS system can be installed through either Windows 3.1, Windows 95, or DOS on a 486 or higher PC. Table 1 summarizes the disk requirements for the system, source code, sample output, and documentation files. On a disk with a cluster size of 32,768 Mbytes, ORAMUS requires approximately 100 Mbytes of space for installing the system, 730 Mbytes for obtaining risk results for all acute health endpoints (90 Mbytes of which are for risk results for the four acute endpoints used in EPA's review of the ozone NAAQS), and 90 Mbytes for obtaining risk results for all chronic endpoints. For a cluster size twice as large, double the requirements; for a sector size half as large, reduce the requirements by $50 \%$.

TABLE 1 Approximate Disk Space Required for Installing ORAMUS (in Megabytes) Compared with Cluster Size

\begin{tabular}{ccccc}
\hline $\begin{array}{c}\text { Cluster } \\
\text { Size }\end{array}$ & System & $\begin{array}{c}\text { Source } \\
\text { Code }\end{array}$ & $\begin{array}{c}\text { Sample } \\
\text { Output }\end{array}$ & $\begin{array}{c}\text { GEN.EXE } \\
\text { Documentation }\end{array}$ \\
\hline 8,192 & 26 & 1.1 & 1.7 & 0.4 \\
16,384 & 52 & 1.3 & 3.4 & 0.4 \\
32,768 & 103 & 1.7 & 6.8 & 0.5 \\
65,536 & 203 & 2.4 & 13.5 & 0.6 \\
131,072 & 406 & 4.5 & 27.0 & 1.0 \\
\hline
\end{tabular}

\section{Windows 3.1 and Windows 95 Installation}

Three installation disks (ORAWIN1-3) contain the Windows 3.1 and Windows 95 installation files required for the ORAMUS system. Follow the procedure below to install ORAMUS on your computer:

1. Place disk ORAWIN1 in drive a: (if your floppy disk drive is a drive other than a:, substitute the appropriate drive name for a: in the following instructions). 
2. In Windows 3.1, click the Program Manager File Run command. In Windows 95, click Start, and then click Run.

3. Type a:oramus95 and click OK.

4. Follow the prompts on the screen for installing ORAMUS. Options for installing the system, the source code, information about GEN.EXE, and sample output files are given. You also can specify that the system be installed in a new or existing directory.

During installation, a program group is created that contains ORAMUS icons. Although ORAMUS is a DOS application, installing it in Windows makes it readily available for Windows users.

\section{DOS Installation}

Three installation disks (ORADOS1-3) contain the DOS installation files for the ORAMUS system. Follow the procedure below to install ORAMUS on your computer:

1. Create an ORAMUS directory at any level on any drive and go to that directory. For example, if you want to put ORAMUS on network drive $\mathrm{y}$ : in a public directory that does not exist, enter the following commands:

\section{y:}

md \public

md \publicloramus

cd \publicloramus

2. Place disk ORADOS1 in drive a: (if your floppy disk drive is a drive other than a:, substitute the appropriate drive name for a: in the following commands).

3. Enter a:orazip1 $-\mathbf{d}{ }^{*}{ }^{*}$. 
4. Place disk ORADOS2 in drive a:.

\section{Enter a:orazip2 -d **.}

Output Files. For headcount risk models, the installation disks contain only the input files needed to create the output files. First, create the output files. It is recommended that you create them in large groups. While it takes only a few seconds to generate one output file, many thousands comprise the full results. Thus, it can take several hours to generate each group of output files. Once the output files have been created, you can quickly view selected results. Section 4 provides instructions on how to create and then view the results of headcount risk. 


\section{GETTING TO KNOW THE ORAMUS SYSTEM}

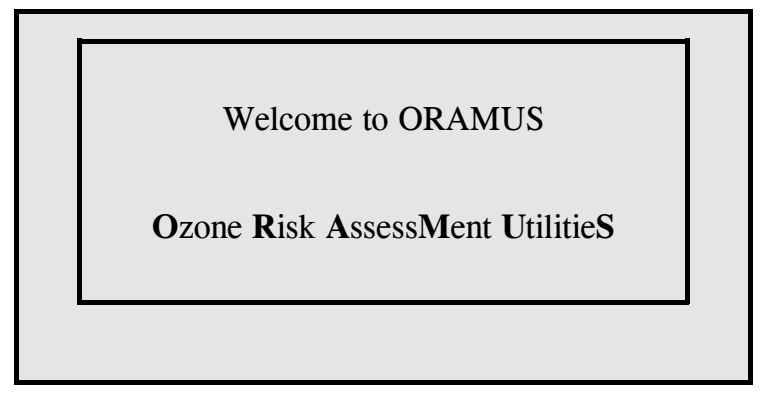

Welcome Screen for ORAMUS

Now that you have installed the ORAMUS software, you are ready to use the system. If you installed ORAMUS under Windows 3.1 or Windows 95, open the ORAMUS folder and double click on the ORAMUS icon. If you want (or need) to run under DOS, follow these steps:

1. At the DOS prompt, change to the ORAMUS directory (e.g., cd Ipublicloramus).

2. Type oramus.

\section{Press Enter.}

If the system has been installed properly, you can proceed as follows. At the Welcome screen, press any key to display the first screen, M000 (the Main Form shown on page 12).

If the system is not installed properly, Form M000 is not displayed. If you cannot reach this form, run the system a second time. After the Welcome screen, Form S000 is displayed, which is a setup form with one field in which you must enter the path to the ..IORAMUS directory. Follow the instructions given in Form S000 and press F10 to proceed. 


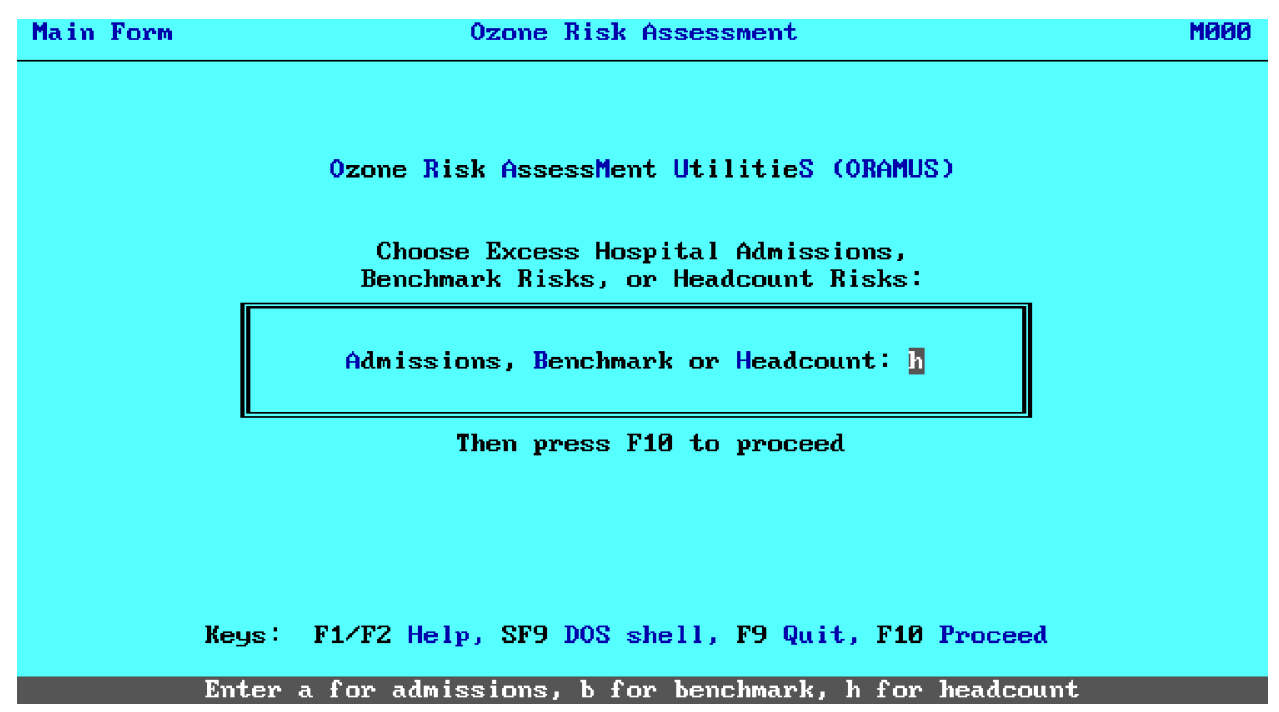

M000 - Main Form for ORAMUS

Using Forms. The user interface for ORAMUS consists of a set of forms used to (a) make branching choices, (b) enter text strings (e.g., a graph title), or (c) select one or more items from a list (e.g., select Chicago from a list of urban areas). While some forms have a large number (more than 100) of display-only and user-accessible areas (called fields), others have only one user-accessible field, which is usually one character wide.

Each form contains a title at the top and one or more fields in which you must input information. Each form also has a listing of function keys that perform special actions. The line at the bottom of the form gives an instruction specific to the current field. In most cases, you can press Esc to return to the previous form. Pressing F10 proceeds to the next step after you have input any necessary data in a form.

Before continuing with the tutorial, it is useful to become familiar with the help features built into ORAMUS. From Form M000, you can access Help screens by using the following keystrokes:

$<$ Press F1 to obtain general help for forms. You can also press F2 for form-specific help. The first Help screen provides information about the keystrokes used to move about the forms. 
$<$ Press F1 twice in any form to see a Help screen that shows the colors selected for the forms.

$<$ In any of these Help screens, press Esc to return to Form M000. The screens associated with these actions are shown on page 14 .

A schematic, which lists the components that make up the ORAMUS system, is shown in Table 2. Formats of principal input and output files are discussed in Appendix A.

Batch Files. As you become familiar with ORAMUS, you will learn that it runs from a series of batch files. As branching decisions are made, additional commands are appended to executing batch files to control more operations. The principal batch files are:

ORAMUS.BAT STARTER.BAT

NEXT.BAT GENEXT.BAT

GOHCBOX.BAT GNEXTINI.BAT 


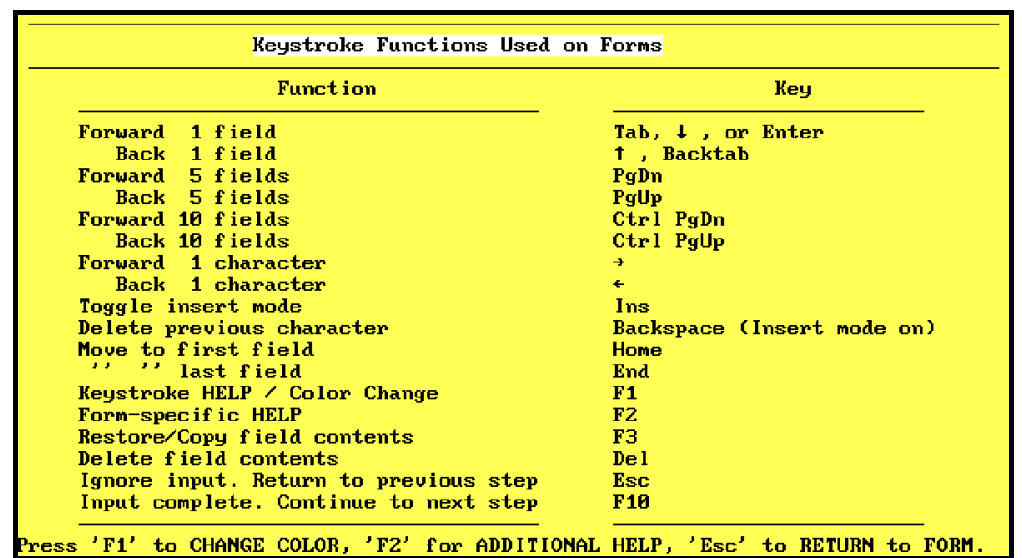

Keystrokes for Moving around in Forms (obtained by pressing $\mathrm{F} 1$ )

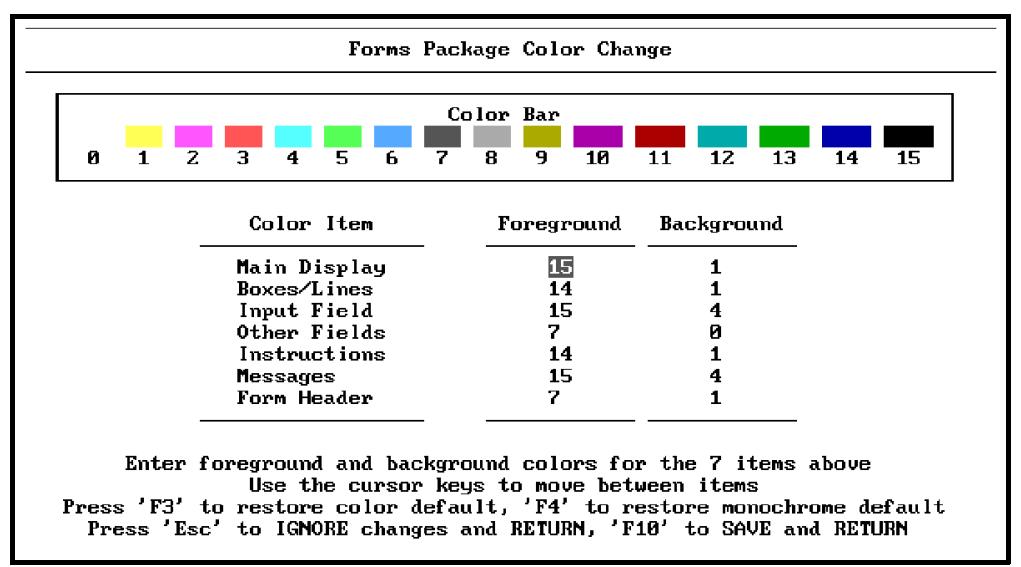

Screen Colors for Forms (obtained by pressing F1 twice)

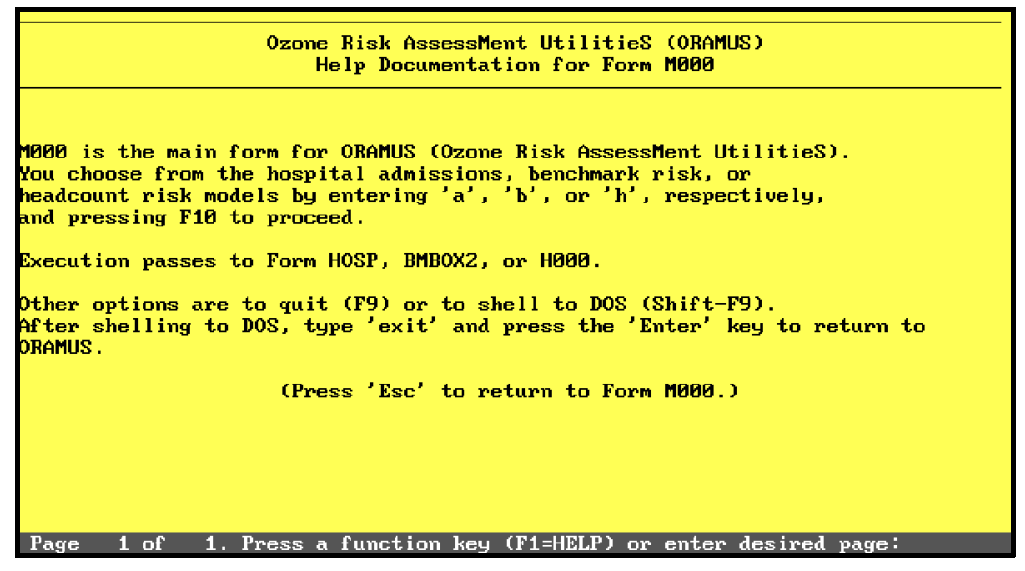

\section{Example of Help Documentation for ORAMUS Forms} (obtained by pressing F2 in Form M000) 


\section{TABLE 2 Schematic for ORAMUS}

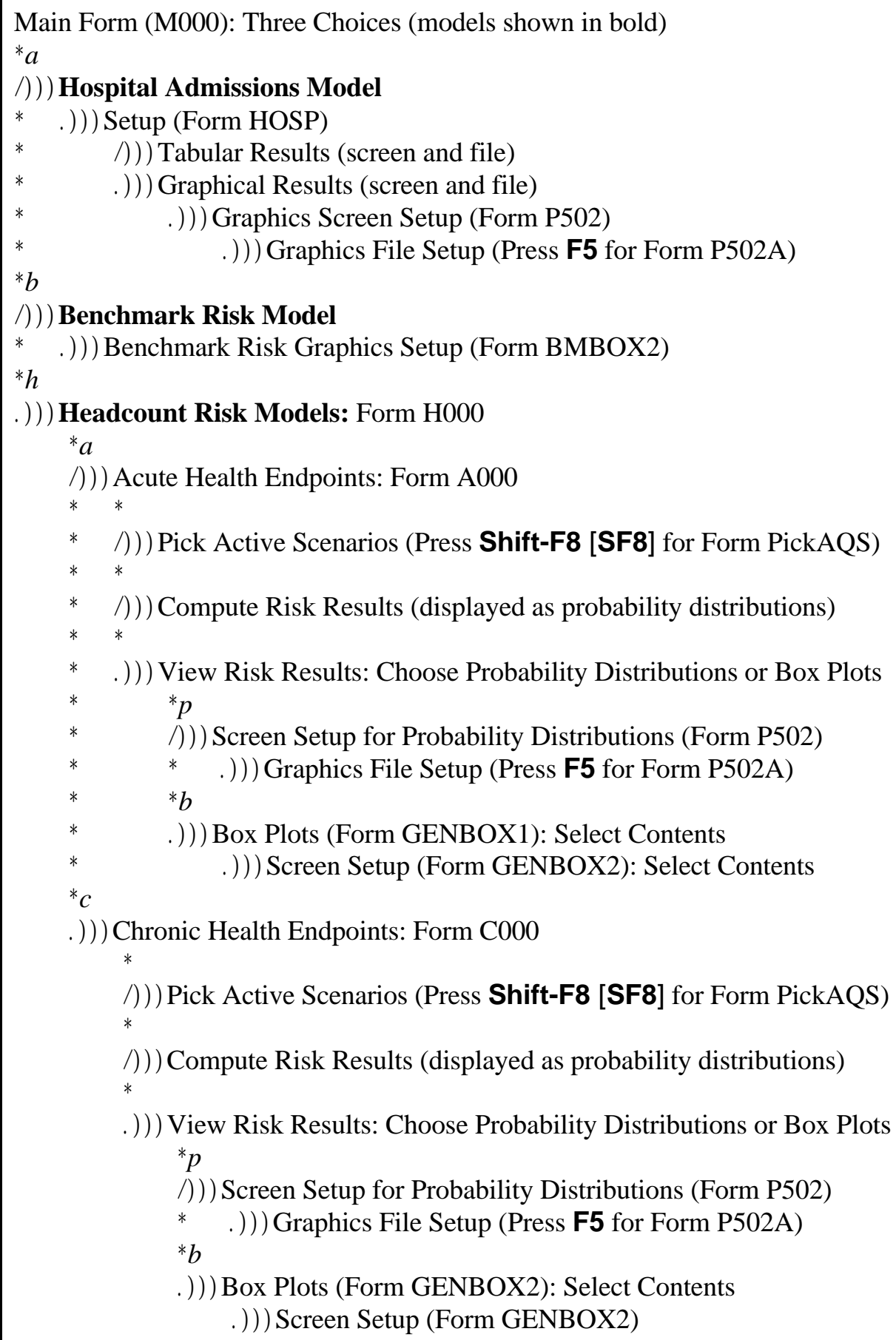


To proceed with the tutorial,

1. In Form M000 (shown on page 12), type $\mathbf{h}$ (for headcount risks). (Note: all entries are case insensitive throughout the program.)

2. To display Form H000 (shown below), press F10 (or Enter). Form H000 is used to select acute or chronic headcount risk models. Headcount risks for chronic health endpoints are discussed in Section 4. Acute risks are discussed in Volume 1.

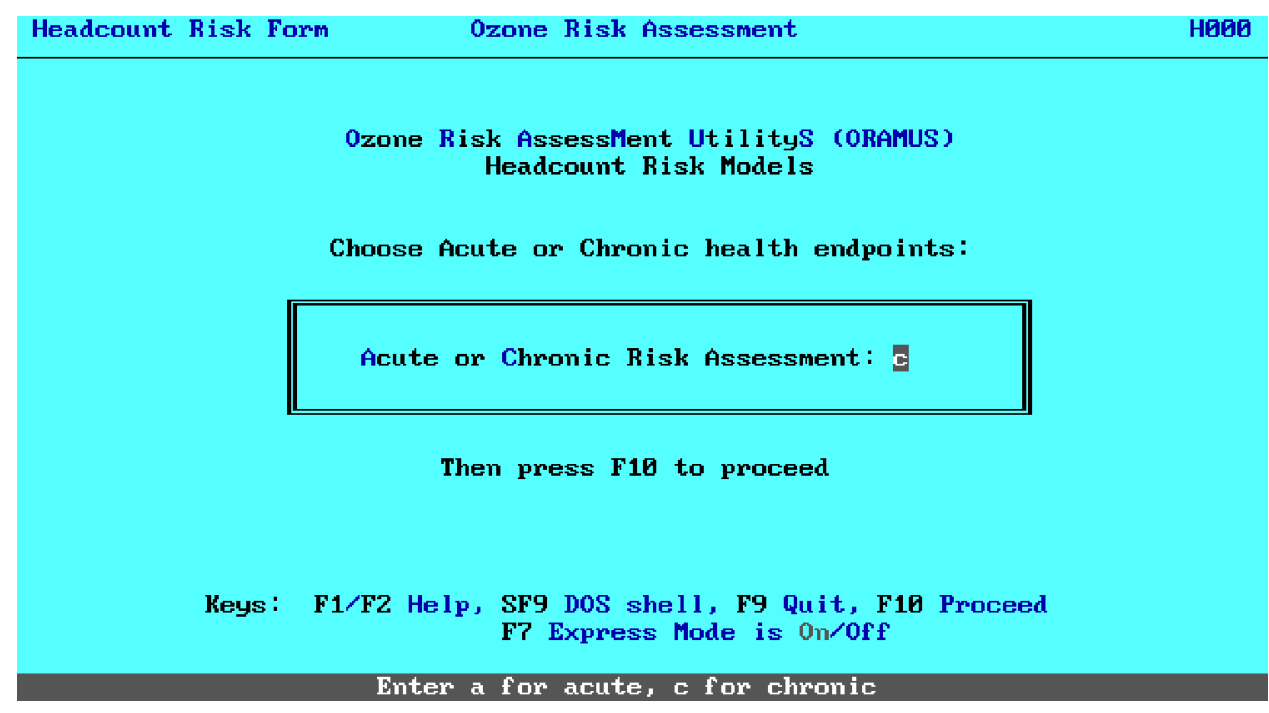

H000 Main Form for Headcount Risk Models 


\section{HEADCOUNT RISKS FOR CHRONIC ENDPOINTS}

Headcount risk looks at the number of persons affected and the number of incidences of a given health effect. This measure takes into account exposures to individuals as they go about their daily activities (e.g., going from indoors to outdoors, moving from place to place, and engaging in activities at different levels of exertion).

\section{Choosing between Acute and Chronic Health Endpoints}

ORAMUS allows you to work with either acute or chronic health endpoints. Acute health endpoints, such as lung function and symptoms, are associated with short-term (1- to 8-hour) exposures to ozone. Chronic health endpoints are associated with long-term (1 or 10 seasons) exposures.

You have already selected $\mathbf{h}$ in Form M000 to reach Form H000, the Headcount Risk Form. The tutorial continues with an example of chronic health endpoints (the alternate choice is for acute health endpoints, which is discussed in Volume 1).

1. In Form H000, type c (for chronic risks).

2. To display Form C000, press F10 (or Enter). This form is the main form used for viewing or computing selected results for chronic health endpoints.

Express Mode. A useful key in Form H000 is F7, which toggles the express mode on and off. The default mode is off. (Note the color change in the words "On" and "Off" to indicate the express mode.) The express mode allows you to skip intermediate screens associated with viewing the results as probability distributions. Details on viewing probability distributions are provided later in this section. 


\section{Setup for Computing or Viewing Selected Risk Results for Chronic Health Endpoints}

The results of controlled human exposure studies formed the basis for estimating exposure-response relationships for acute health endpoints; however, it was necessary to use expert judgment to estimate these relationships for chronic health endpoints (Whitfield et al. 1991; Winkler et al. 1995). Form C000 is the main form used for selecting the following:

$<\operatorname{Expert}(\mathrm{A}, \mathrm{B}, \mathrm{C}, \mathrm{D}$, or F),

$<$ Health endpoints (mild or moderate centriacinar lesions),

$<$ Urban area (Los Angeles or New York City),

$<$ Populations (outdoor children or outdoor workers),

$<$ Number of seasons of exposure to ozone (1 or 10$)$, and

$<$ Air quality scenarios for which risk results are to be computed or viewed.

Except for Expert E, all experts agreed to have their judgments used in a risk assessment at this time. Expert E was uncomfortable because of the number of years that had passed since the judgments were obtained and felt that recent results, on which Expert E was not current, might lead to different judgments. These items are organized into seven sections. If you need complete risk results, you should compute them in large blocks, as indicated in Form C000.

Health Endpoint Names. A strict naming convention is used for chronic risk output files. You are not at liberty to change file names; doing so would produce undesirable results. You do not have to be concerned with this matter because ORAMUS creates and names all risk output files. You need only understand the meaning of the names. The file naming conventions for chronic health endpoints are explained later in this section. 
In Form C000, selected items are marked with an asterisk. These items are all experts, lesions, urban areas, populations, ozone seasons, and scenarios.

$<$ To include (mark) an item, press F4. Doing so places an asterisk in the field and advances to the next field.

$<$ To exclude (unmark) an item, press F5. Doing so places a blank in the field and advances to the next field.

$<$ To clear all marks, press Shift-F4 (SF4).

$<$ To open a DOS shell, press Shift-F9 (SF9).

$<$ To return to Form H000, press F9.

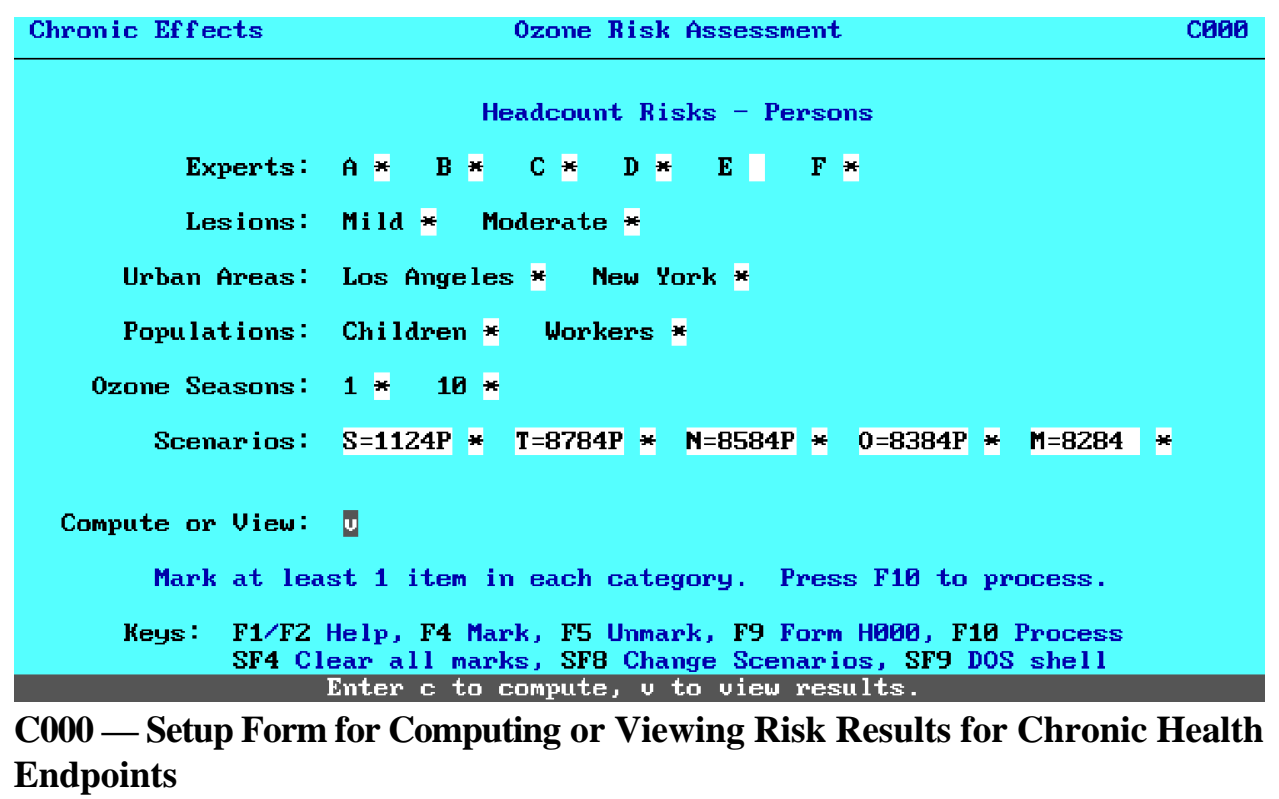

\section{Specifying Active Air Quality Scenarios}

Although only 5 scenarios are shown in Form C000, you can select from as many as 10. Limiting the maximum number of "active" scenarios to 10 is necessary to produce readable graphs. To specify which scenarios are active, follow these steps:

1. Press Shift-F8 (SF8) to display Form PickAQS (shown on page 20). 
2. For practice, unmark Scenario M (by pressing CursorUp [8], CursorUp, F5) and press F10.

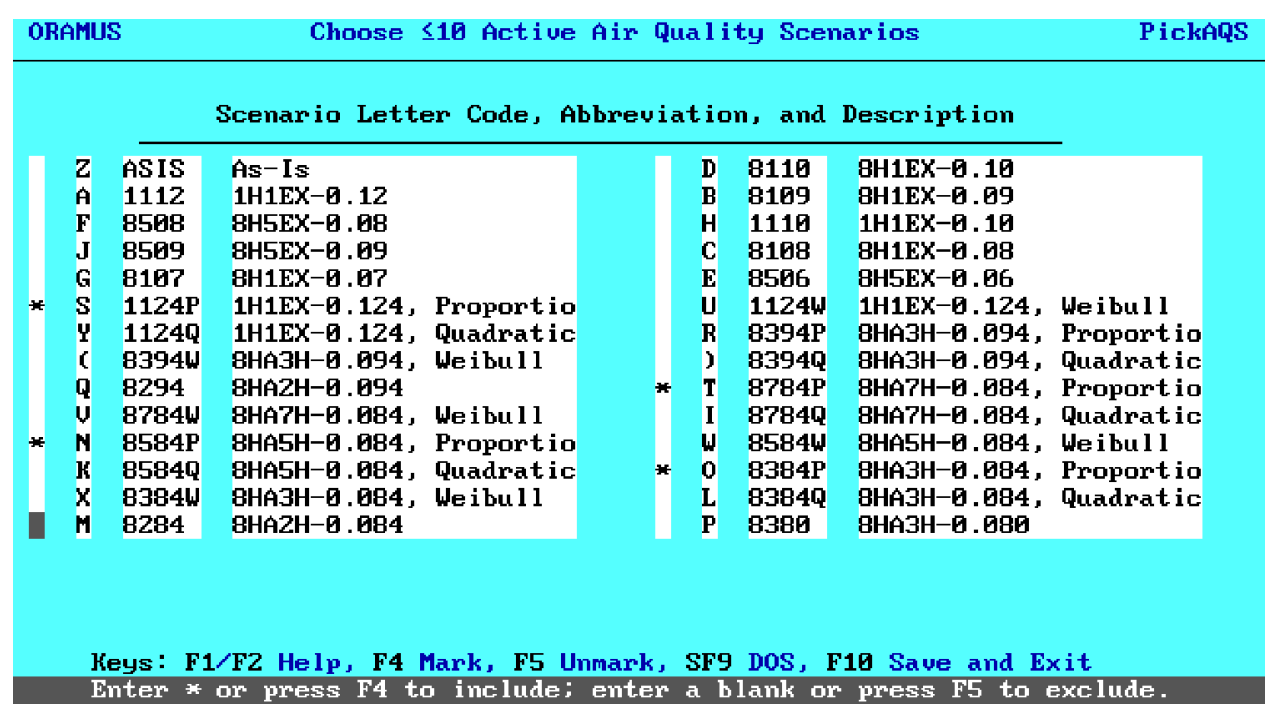

PickAQS — Form for Selecting Active Air Quality Scenarios

After a series of DOS commands has been completed, Form C000 is again displayed. Scenario M is not listed because you unmarked it in Form PickAQS. 
Scenario Information. A total of 27 scenarios are available for chronic health endpoints: 26 alternative NAAQS and 1 scenario that represents current (As-Is) air quality for 1990 or 1991 (i.e., the data for a specific urban area are either 1990 or 1991 data). Your choices, which are saved in the file PickAQS.sav, are in effect for computing or viewing headcount risks and hospital admissions.

Pressing F10 in Form PickAQS executes the DOS ATTRIB command, which hides risk output files for unmarked air quality scenarios and unhides files for marked scenarios. Consequently, to compute risk results for all 27 scenarios for a particular group of health endpoints, you need a minimum of three selection steps and subsequent computation steps for each population. It is most efficient to compute risk results for all experts, lesion types, urban areas, populations of interest, and ozone seasons before changing the scenario set. The program returns to, in this case, Form C000. You can also access Form PickAQS from Form A000, Form HOSP, and DOS.

\section{Setup for Computing Selected Risk Results for Chronic Health Endpoints}

To continue with the tutorial, follow the instructions below to shorten the run time for the computation step.

1. Press Shift-F4 (SF4) to clear all marks.

2. In the "Experts" section, mark all fields. (Note that you will not be able to include Expert E.)

3. In the "Lesions," "Cities," "Populations," and "Seasons" sections, mark Mild, Los Angeles, Children, and 1, respectively.

4. In the "Scenarios" section, mark the first four scenarios.

5. In the "Compute or View" section, type c to specify computing risks. Form $\mathrm{C} 000$ should now display the data in the screen shown on page 22 . 
6. Press F10 to begin to compute results for the selections you made.

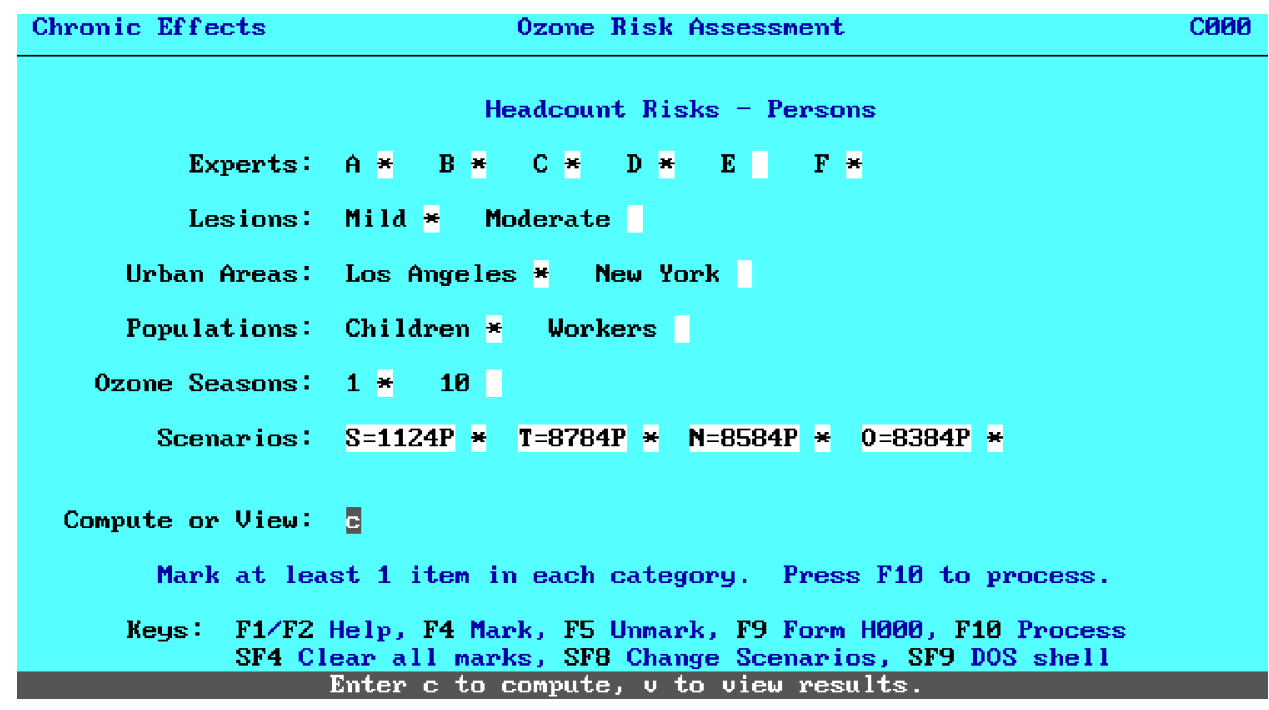

Setup for Computing Selected Risk Results for Chronic Health Endpoints

Several DOS messages are displayed (giving you the names of input and output files). A message then notifies you that no graphics can be produced because more than one item has been marked in two or more sections, which makes it impossible to produce graphics. The program then returns to Form C000.

\section{Directory Structure and File Naming Conventions}

Under the ORAMUS directory, results for 1-hour exposures at heavy exertion health endpoints are written in the 1HR directory; results for 1-hour exposures at moderate exertion health endpoints are written in the 2HR directory; and results for 8-hour exposures at moderate exertion health endpoints are written in the 8HR directory. In addition, results for chronic health endpoints are written in the CHRONIC directory; results for hospital admissions are written in the HOSPITAL directory; and benchmark risk results are stored in the BENCHMRK directory. The naming conventions for chronic risk output file specifications are listed in Table 3 . 
TABLE 3 File Naming Conventions for Chronic Health Endpoints

\begin{tabular}{|c|c|c|}
\hline $\begin{array}{l}\text { Character } \\
\text { Position }\end{array}$ & Significance & Example \\
\hline \multicolumn{3}{|l|}{ Filename } \\
\hline 1 & Expert & A for Expert A, etc. \\
\hline 2 & Lesion type & I for mIld and $\mathrm{O}$ for mOderate \\
\hline 3 & Urban area & L for Los Angeles, $\mathrm{N}$ for New York City \\
\hline 4 & Population & $\begin{array}{l}\text { C for outdoor children, } \mathrm{W} \text { for outdoor } \\
\text { workers }\end{array}$ \\
\hline 5 & Exposure duration & $\begin{array}{l}\text { O for } 1 \text { ozone season, } \mathrm{T} \text { for } 10 \text { ozone } \\
\text { seasons }\end{array}$ \\
\hline 6 & Air quality scenario & $\begin{array}{l}\mathrm{Z} \text { for As-Is; A for } 1 \text { hour, } 1 \text { expected } \\
\text { exceedance, } 0.12 \text { ppm of ozone; } \mathrm{V} \text { for } \\
8 \text { hours, seventh highest maximum, } \\
0.084 \text { ppm of ozone, Weibull rollback; etc. }\end{array}$ \\
\hline \multicolumn{3}{|l|}{ Extension } \\
\hline 1 & Headcount & $\mathrm{H}$ (required) \\
\hline 2 & Risk measure & $\mathrm{P}$ for persons \\
\hline 3 & Risk & $\mathrm{R}$ (required) \\
\hline
\end{tabular}

\section{Viewing Risk Results as Probability Distributions}

To continue with the tutorial, perform the following steps:

1. Unmark Experts B, C, D, and F (i.e., only Expert A should be marked).

2. Move to the "Compute or View" section.

3. Press $\mathbf{v}$ to view.

4. Press F10 to proceed. You will notice a pause - indicated by a beep tone - after setup information is displayed. To terminate this (or any) pause and continue, press any key. 
5. Once you have terminated the display of setup information, you can choose to view the output either as probability distributions or as box plots (Form PorB).

6. To select probability distributions, type $\mathbf{p}$.

7. Press F10 to proceed. Statistics about the risk distributions are displayed for each air quality scenario.

8. Press any key to see a list of selected air quality scenarios; you must choose one scenario as a reference. It is often desirable to choose the scenario associated with the largest risks as your reference scenario.

9. To choose $1124 \mathrm{P}$ as the reference scenario, type 1 .

10. To display a graph of risk distributions, press Enter.

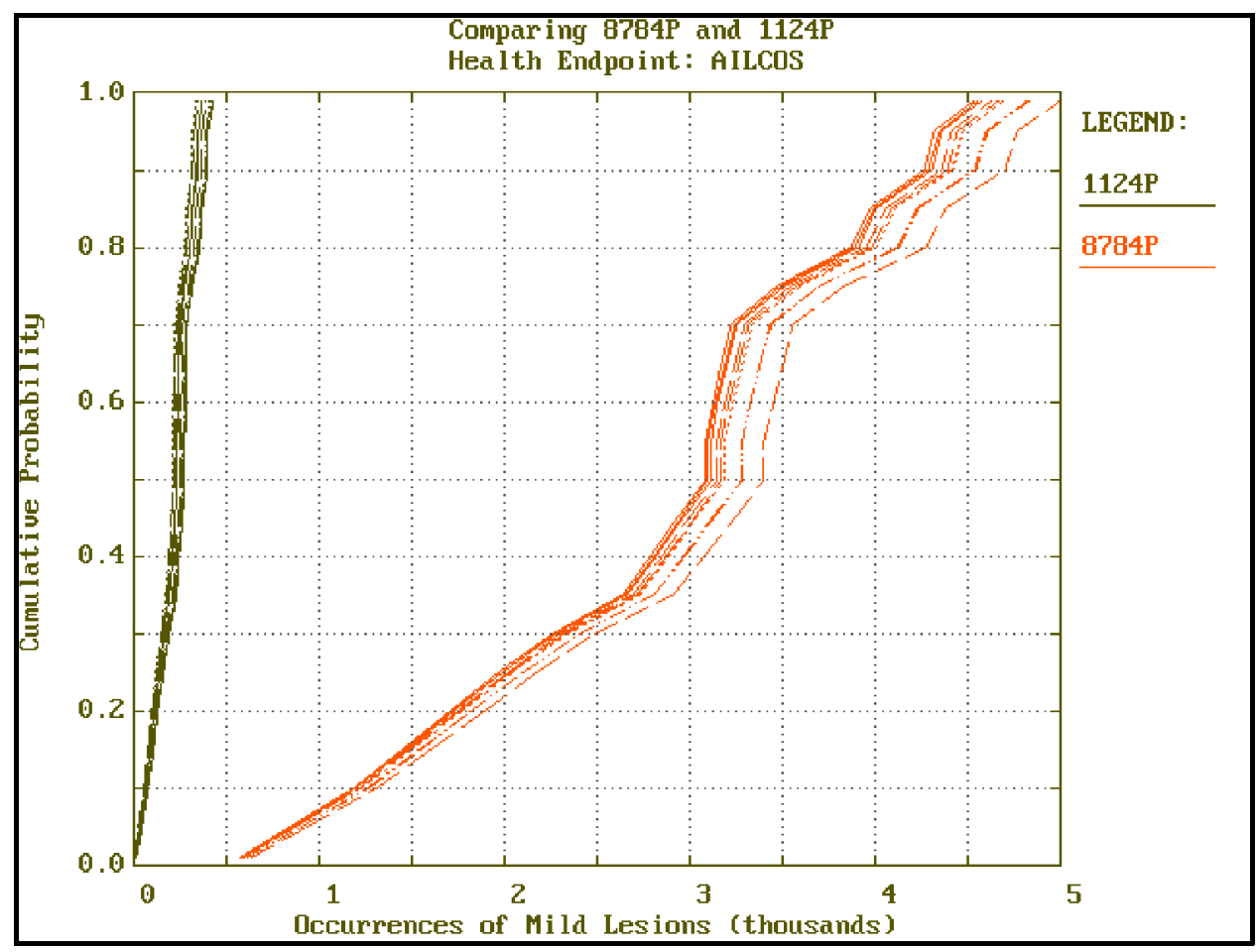

A Set of 10 Risk Distributions for Each of 2 Air Quality Scenarios 
Graphs. The screen displayed on page 24 is a graph of two sets of probability distributions over the number of children who may develop mild centriacinar lesions after exposure to ozone for one ozone season. (Note: press $\mathbf{F} \mathbf{1}$ or $\mathbf{F} \mathbf{2}$ for help. The grid lines can be toggled on and off by repeatedly pressing $\mathbf{g}$.) Each set has 10 probability distributions because there are $10 \mathrm{pNEM} / \mathrm{O}_{3}$ runs for each air quality scenario. There is one set for each of two air quality scenarios. In the current example, variability occurs among runs, which is indicated by the spacing between the 10 distributions in each set.

The tutorial now moves forward to the next form, which allows you to modify the axes.

1. To proceed to Form P502, press any key. In this form, you can modify the $\mathrm{X}$ - and $\mathrm{Y}$-axes.

2. To regraph the data, press F9. Note the improvement in the $\mathrm{X}$-axis format. Press any key to return to Form P502. Use the up/down arrows to move to the required boxes. Modify the values to those displayed in Form P502 (shown below).

3. To proceed to the next graph, press F10. For the current example, two more graphs will follow, which will complete the three possible comparisons of the reference scenario to the remaining selected scenarios.

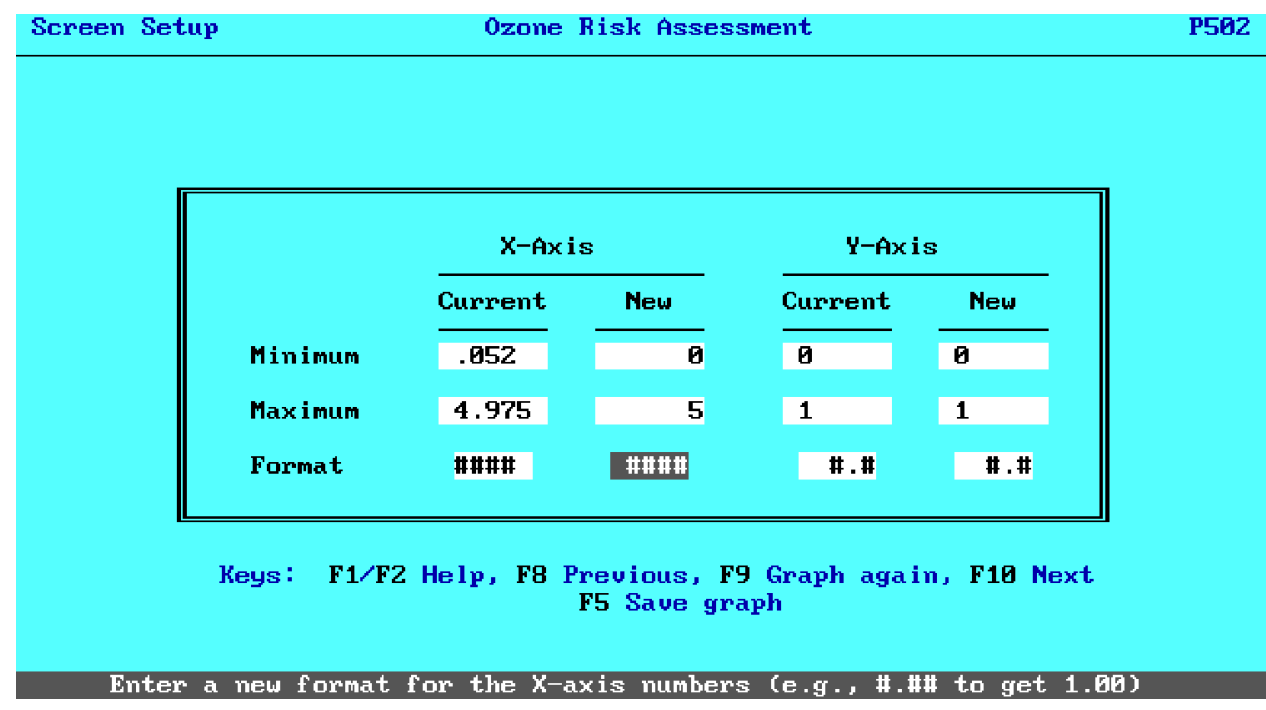

P502 Form for Controlling Graph Properties 


\section{Representative Distributions and Vector Graphics Images}

After all comparisons with the reference scenario have been displayed, a figure with one distribution that is "representative" of each set of 10 distributions is displayed.

To create a vector graphics data file for this graph, proceed as follows:

1. To display Form P502, press any key.

2. Press $\mathbf{F} \mathbf{5}$ to start the process of saving the data (in an ASCII file) to later create a vector graphics data file (in WordPerfect Graphics [WPG] format).

3. After a pause during which data for the graph are displayed, press any key to display Form P502A. Modify the values as shown in the form below. You can specify titles, axis labels, data ranges, formats, and an output filename.

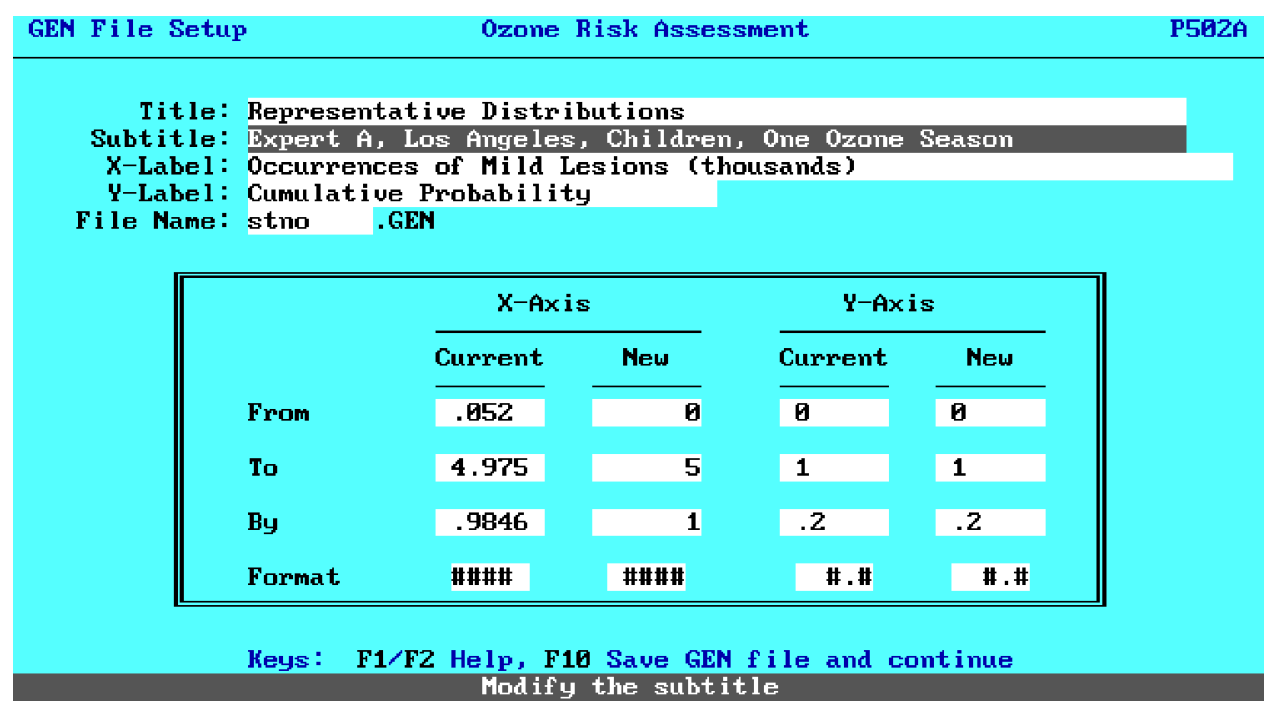

P502A — Form for Controlling Properties of a WordPerfect Graphics Image

4. Press F10 to save the vector graphics data file and then display another graph showing the differences between the reference scenario and the other scenarios. 
Because of memory limitations, it is not possible to create the vector graphics data file while ORAMUS is running (unless you are running under Windows). After you exit ORAMUS, you can create vector graphics data files (in WPG format) as discussed later.

WPG Files. The figure shown below is an example WPG image that can be created by using ORAMUS and GEN.EXE. For more information on using GEN.EXE, see the user's guide (Jusko and Whitfield 1996) included on the installation disk (GENPLOT.W51, a WordPerfect 5.1 document) or the discussion on pages 31 and 32 .

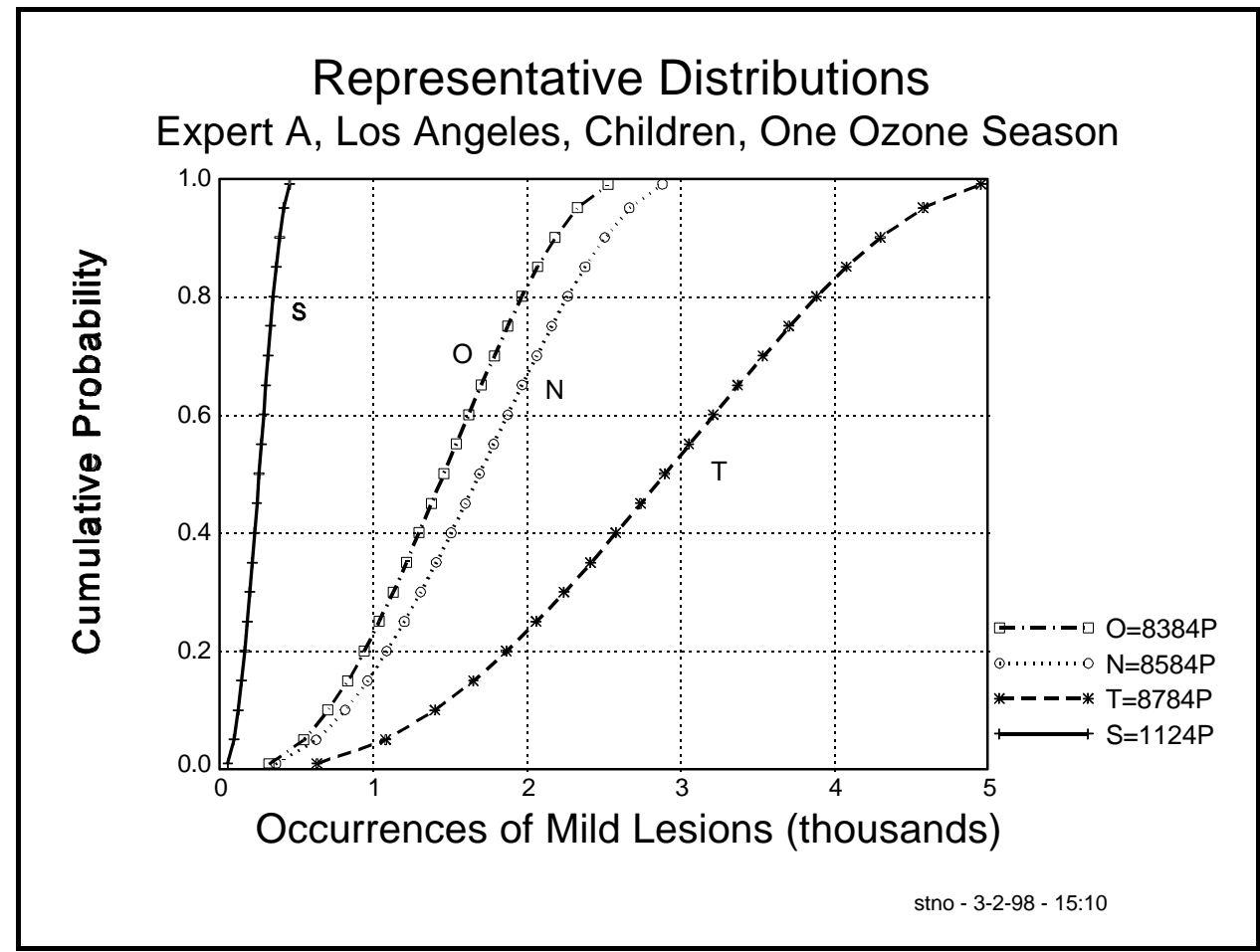

Example of a WordPerfect Graphics Image 


\section{Differences between the Reference Scenario and Other Scenarios}

After saving the graphics data or simply viewing the screen that shows the representative distributions, ORAMUS displays a screen (shown below) that shows the differences between the reference representative risk distribution and the other distributions. These differences are displayed as probability distributions. Exiting the screen setup form that follows this graph returns you to Form C000.

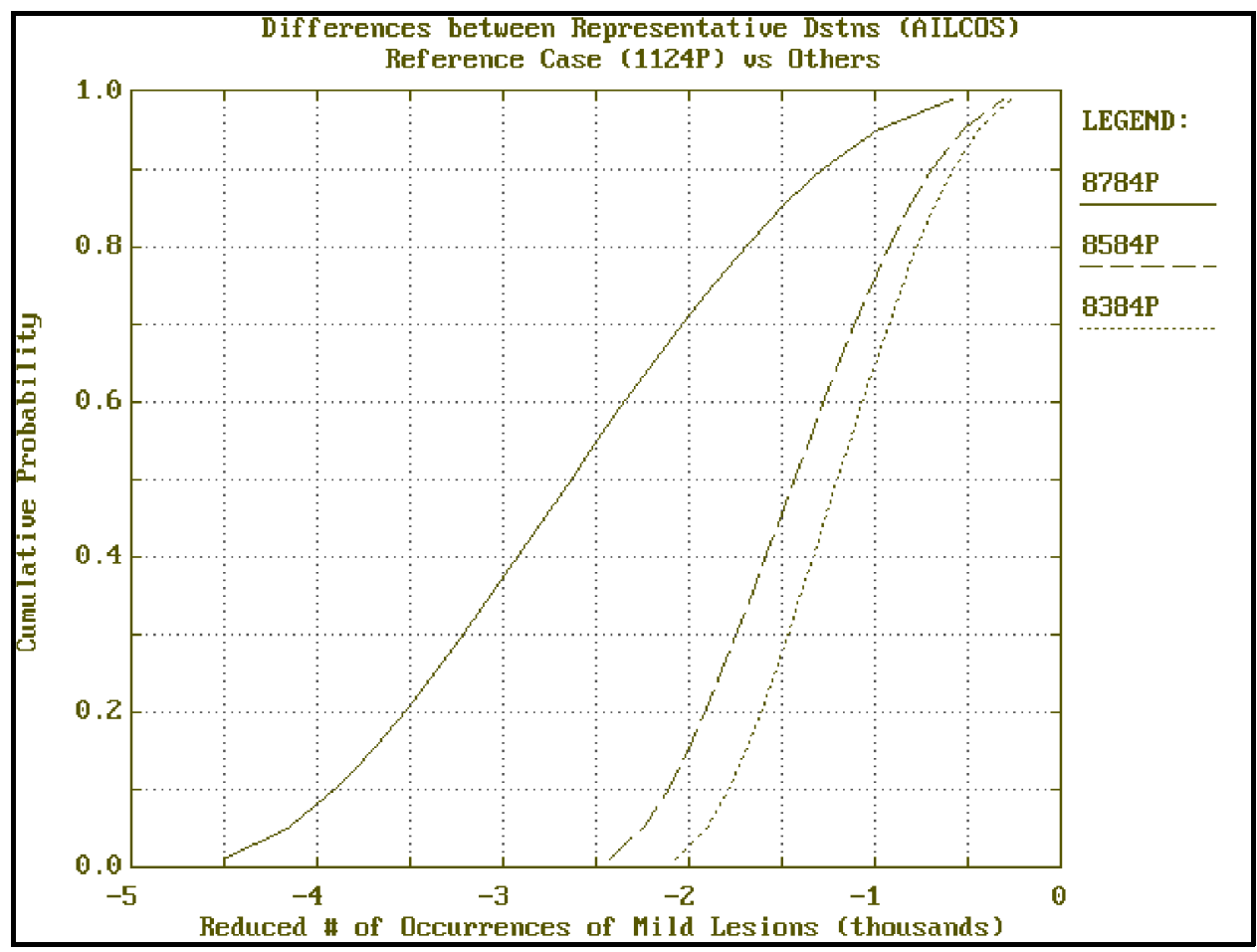

Differences between the Reference Representative Distribution and Other Distributions

\section{Viewing Risk Results in Box Plot Format}

This portion of the tutorial takes you through the steps needed to view the risk results as box plots rather than as probability distributions.

1. Return to Form C000. The settings for viewing the results should still be displayed. Press F10 to display selection information, which is followed by a pause. 
2. Press any key to end the pause and display Form PorB.

3. Type $\mathbf{b}$ for box plots and press F10.

Box Plots. It is important at this time to note a critical constraint on box plot graphs. The number of output files must exactly match the number of urban areas times the number of air quality scenarios. In the current example, this requirement is met.

Four scenarios are active (S, T, N, and $\mathrm{O})$. All have abbreviations that end in the letter $\mathrm{P}$, meaning that results can be computed for proportional, Weibull, and quadratic air quality adjustment procedures. Some abbreviations (e.g., 8284, which you removed from consideration in Form PickAQS) do not end with the letter P, meaning that results are not available for Weibull or quadratic air quality adjustment procedures. Furthermore, there are no Weibull or quadratic exposure estimates for the "earlier" air quality scenarios. Therefore, attempts to display box plots for scenarios that have "complete" results (i.e., for all three air quality adjustment procedures) along with scenarios that do not have complete results will fail if data are "missing." If you follow the instructions for specifying active air quality scenarios (given on page 19), you can avoid this pitfall.

4. Type $\mathbf{y}$ to acknowledge that you want to view/change the active air quality scenarios. Pressing $\mathbf{y}$ automatically takes you to Form PickAQS.

5. If Scenario $M=8284$ is still active, remove it (i.e., unmark it) from the active list and press F10. Wait until a series of DOS commands are executed, and Form GENBOX1 is displayed. (These commands hide "unwanted" air quality scenarios by using the DOS ATTRIB command.) If Scenario $M$ is not active, press Esc to display Form GENBOX1.

6. Modify the fields in Form GENBOX1 as indicated in the screen on the following page.

7. To proceed to a graph setup screen (Form GENBOX2), press F10. 


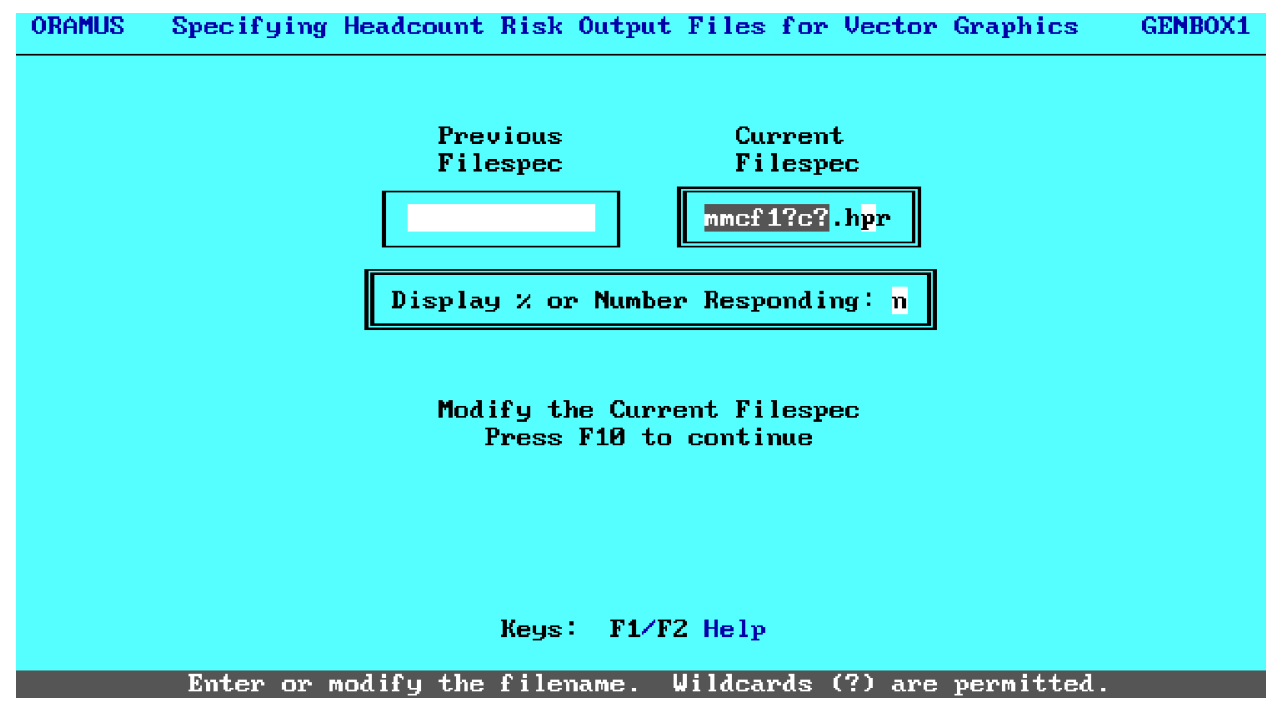

GENBOX1 — Form for Specifying the Contents of a Box Plot

Discussion. In Form GENBOX1, the entries in the Current Filespec box specify that the graph will include results based on the judgments of Experts A, B, C, D, and F (indicated by the first question mark) about the formation of mild lesions among children after exposure for one ozone season for all active air quality scenarios (indicated by the second question mark; in this case, four scenarios will be included). The $p$ in the extension $h p r$ means to include results for the persons measure (rather than person-occurrences). The $N$ in the "Display" field means to display results in terms of the number of children responding (rather than percent responding). For chronic endpoints, the persons and person-occurrences measures are the same. ORAMUS creates results only for the persons measure.

8. Enter the data indicated in Form GENBOX2 shown on the next page. The key modifications to make in the section labeled "New" are to change the units to $\mathbf{k}$ for thousands and change the "to" and "by" values to $\mathbf{1 8}$ and 2, respectively. These changes result in a graph that is easier to read. A box plot (a vector graphics image) is shown following Form GENBOX2 on the next page.

9. To proceed to the next box plot, press F10. 


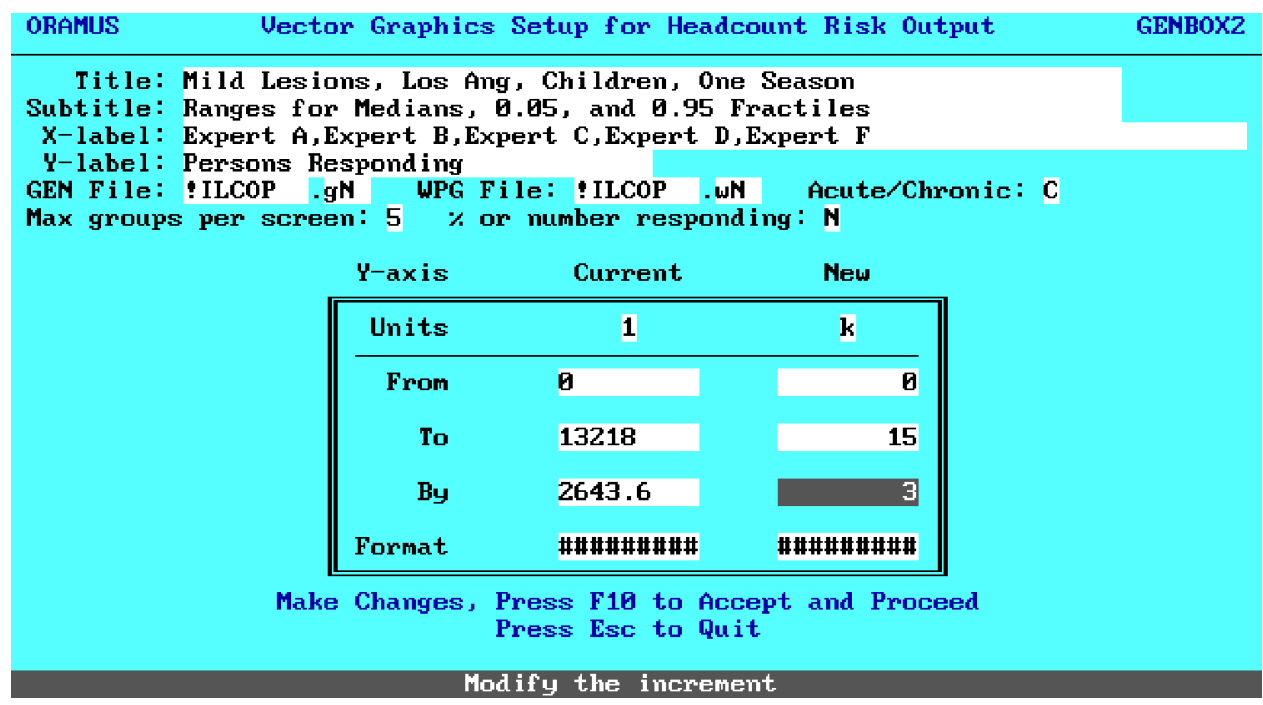

GENBOX2 - Form for Specifying the Appearance of the Box Plot

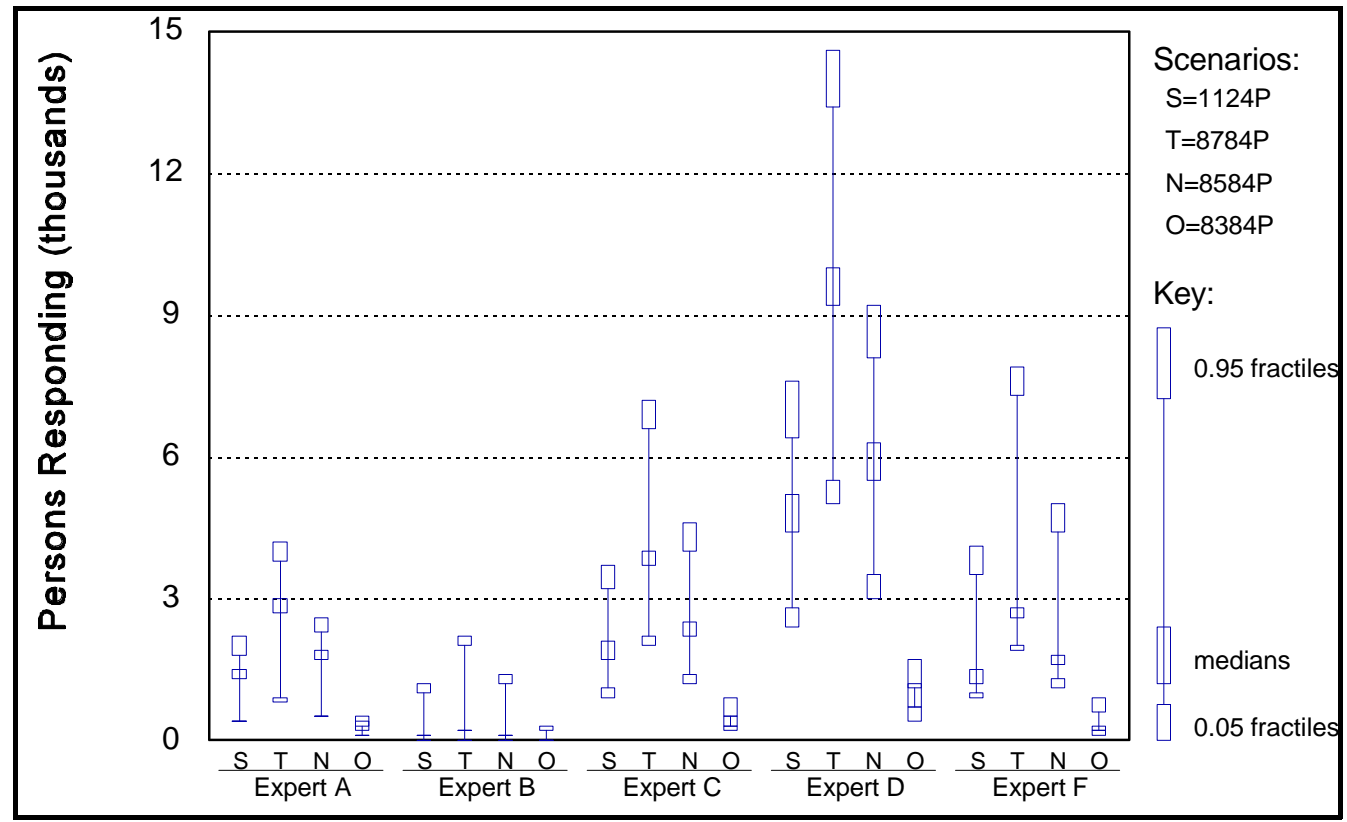

Vector Graphics Image of the Box Plot Format for Chronic Risk Results (all experts, mild lesions, Los Angeles, children, exposure for one ozone season, four air quality scenarios)

\section{Creating a Vector Graphics Image File}

If you are running ORAMUS under DOS, you must create a vector graphics image file while ORAMUS is not running. To begin this process, exit ORAMUS. If you have been following the tutorial and Form C000 is displayed, press Esc four times to exit ORAMUS. (If you 
are running under Windows, you can continue to run ORAMUS if you open a new DOS window.)

In the ORAMUS directory, enter the following DOS commands:

1. cd chronic.

2. ...gen stno.gen stno.wpg nul.

The screen displays a figure that resembles the graph of representative distributions shown on page 27 , which has been enhanced in a graphics editor (scenario code letters were added to identify each distribution, and the text "legend" was added to identify the legend). Note that the second parameter of the GEN command is a file specification (stno.wpg); this file is a vector graphics image file that can be incorporated into a word processing document or modified in a graphics editor. The third parameter is reserved for the name of an HP Graphics Language (HPGL) file. In this case, no HPGL file was created because "nul" was specified. If you want to create an HPGL file, specify a legitimate file specification (e.g., stno.hpg). 


\section{FINAL NOTES}

\section{An Extra Utility — LOOKERF.EXE}

LOOKERF.EXE is an extra utility that allows you to graph selected exposure-response relationships (for 1-hour exposures at heavy exertion, 1-hour exposures at moderate exertion, 8-hour exposures at moderate exertion, and exposures for either 1 or 10 ozone seasons).

1. Change to the ORAMUS directory and enter the DOS command lookerf. (In Windows, double click the LOOKERF icon.)

2. Follow the prompts. At the first prompt, press $\mathbf{c}$ for chronic.

3. When you are asked to provide a filename, you can, for example, enter $\mathbf{a}^{\star}$ to view all exposure-response relationships based on the judgments of Expert A.

4. When a graph is present on the screen, press F8 to begin the process of creating a vector graphics image file.

As described on page 26, you can control titles, axis labels, and data ranges for the graph. The results are saved in a [filename].GEN file, which is an ASCII file. You can then process the .GEN file by using GEN.EXE to create a WordPerfect graphics ([filename].WPG) file, which can be included in a document.

\section{FIXSAV.BAT}

If an unrecoverable error corrupts key "save" files (namely, A000.sav, C000.sav, and PickAQS.sav), go to DOS, change to the ORAMUS directory, and enter fixsav. FIXSAV.BAT restores earlier versions of these three files (that have the extensionSA@), which should be intact. 


\section{GEN.EXE - A Vector Graphics Generator}

The vector graphics generator, GEN.EXE, is included in the complete installation of ORAMUS. You can copy it to a directory specified in your path for uses other than ORAMUS. Note, however, that GEN.EXE must be in the ORAMUS directory for graphing functions in ORAMUS to work properly.

1. To obtain help on GEN.EXE, at the DOS prompt, enter either gen ? or gen $-\mathbf{h}$.

2. Unless otherwise specified, GEN.EXE will try to create WPG and HPGL files on the d: drive. You will get errors if it is not possible to write to the d: drive. To override this restriction, either specify legal file names (or any valid drive in any valid directory) or use NUL. For example, to generate a screen version of the file defined in GEN.DAT without producing a WPG or an HPGL file, enter gen gen.dat nul nul.

The default names of the WPG and HPGL files are d: GEN.WPG and d: GEN.HPG, respectively.

3. To produce a WPG file but not an HPGL file, enter gen gen.dat gen.wpg nul.

Be careful not to use GEN.DAT as the name for the WPG file or the HPGL file. If you do, you will lose the input data file.

To install the sample files relating to GEN.EXE, create and change to a directory of your choosing (to avoid confusion, it is recommended that you not install the sample output files in the ORAMUS directory structure) and perform the following steps:

1. Place disk ORADOS3 in drive a:.

\section{Enter a:genplot.}

The self-extracting ZIP file GENPLOT.EXE contains sample input and output files and a user's manual. 


\section{Installation and Use of the ORAMUS Source Code}

If you ordered the Windows installation disks, you have an option to install the source code during the installation process. If you ordered the DOS installation disks, follow the instructions below to install the source code for ORAMUS.

1. Return to the ORAMUS directory.

2. Place disk ORADOS3 in drive a:.

3. Enter a:oracode1 $-\mathbf{d}^{*} . *$.

4. Enter cdl.

5. Enter a:oracode2 $-d^{*} . *$.

The source code and other related files will be copied to their respective directories. The contents of ORACODE1.EXE and ORACODE2.EXE are listed in ORACODE.DIR.

The source code looks for 'INCLUDE' files in a c:IBASEDATA directory. (This is not a strict requirement; however, you have to make extensive changes to the source code if you want to move files from the c:(BASEDATA directory.)

The FORMS package provides functions and subroutines for moving data in and out of forms. Source codes for the suite of FORMS package programs included in the installation disks are FORM.BAS, PAGER.BAS, FORARR.BAS, ATON.BAS, and FMENU.BAS. In addition, two library files are provided that contain all of the FORMPACK functions and subroutines. One library file is for use in the QuickBASIC environment; the other is for use in compiling programs in DOS.

To work with one of the ORAMUS source files that must be linked to FORMPACK, enter the following DOS command:

QBX hcmain /I [drive:] lformslformpack. 
This command loads HCMAIN.BAS (and the files listed in HCMAIN.MAK) and links to FORMPACK.QLB. It is convenient to compile ORAMUS programs in the QuickBASIC environment. If you wish to work outside the QuickBASIC environment, pay attention to the messages displayed in the QuickBASIC environment as it compiles and links programs.

\section{Sample Output Files}

Sample output files are included on disk ORADOS3 in SAMPLOUT.EXE, a self-extracting ZIP file. To retrieve these files to the current directory (to avoid confusion, it should not be a directory used by ORAMUS), at the DOS prompt, enter

a:samplout.

If you ordered the Windows installation disks, the sample output files will be copied to a directory named $\backslash$ ORASAMPL on drive $\mathrm{c}$ : if you choose to install them.

\section{Running ORAMUS Executables Directly in DOS}

The box plot module can be run directly in DOS (without the "aid" of ORAMUS). In the ORAMUS directory, enter

\section{gohcbox.}

In Windows, double click the BOXPLOT icon.

The benchmark risk model and the hospital admissions model also can be run separately. To learn about these and other subtleties, occasionally check the contents of the NEXT.BAT, GENEXT.BAT, and BENCHMRKIGENEXT.BAT files. 


\section{REFERENCES}

Johnson, T., 1997, Sensitivity of Exposure Estimates to Air Quality Adjustment Procedure, letter report prepared by TRJ Environmental, Inc., Chapel Hill, N.C., and IT Air Quality Services, Inc., Cary, N.C., for the U.S. Environmental Protection Agency, Office of Air Quality Planning and Standards, Research Triangle Park, N.C., June 20.

Johnson, T., et al., 1996a, Estimation of Ozone Exposures Experienced by Urban Residents Using a Probabilistic Version of NEM and 1990 Population Data, prepared by IT Air Quality Services, Inc., Cary, N.C., for the U.S. Environmental Protection Agency, Office of Air Quality Planning and Standards, Research Triangle Park, N.C., Apr.

Johnson, T., et al., 1996b, Estimation of Ozone Exposures Experienced by Outdoor Workers in Nine Urban Areas Using a Probabilistic Version of NEM, prepared by IT Air Quality Services, Inc., Cary, N.C., for the U.S. Environmental Protection Agency, Office of Air Quality Planning and Standards, Research Triangle Park, N.C., Apr.

Johnson, T., et al., 1996c, Estimation of Ozone Exposures Experienced by Outdoor Children in Nine Urban Areas Using a Probabilistic Version of NEM, prepared by IT Air Quality Services, Inc., Cary, N.C., for the U.S. Environmental Protection Agency, Office of Air Quality Planning and Standards, Research Triangle Park, N.C., Apr.

Johnson, T., et al., 1997, Supplement to Estimation of Ozone Exposures Experienced by Outdoor Children in Nine Urban Areas Using a Probabilistic Version of NEM, prepared by TRJ Environmental, Inc., Chapel Hill, N.C., and IT Air Quality Services, Inc., Cary, N.C., for the U.S. Environmental Protection Agency, Office of Air Quality Planning and Standards, Research Triangle Park, N.C., Jan.

Johnson, T.R., et al., 1990, "Estimation of Ozone Exposure in Houston Using a Probabilistic Version of NEM," Paper No. 90-150.1, presented at the 83rd Annual Meeting of the Air and Waste Management Association, Pittsburgh, Pa., June.

Jusko, M.J., and R.G. Whitfield, 1996, GENWPG: A WPG Graphics File Generator, Argonne National Laboratory, Argonne, Ill., Sept. 9. 
McCurdy, T., 1994, "Human Exposure to Ambient Ozone," in Tropospheric Ozone: Human Health and Agricultural Impacts, D.J. McKee, editor, Lewis Publishers, Inc., Boca Raton, Fla.

McCurdy, T., et al., 1991, "Preliminary Analyses of Ozone Exposures in Houston Using $\mathrm{pNEM} / \mathrm{O}_{3}$," paper presented at the 84th Annual Meeting of the Air and Waste Management Association, Vancouver, B.C., Canada, June.

Paul, R.A., et al., 1986, National Estimates of Exposure to Ozone under Alternative National Standards, prepared for the U.S. Environmental Protection Agency, Research Triangle Park, N.C.

Whitfield, R.G., et al., 1991, Assessing the Risk of Chronic Lung Injury Attributable to Ozone Exposure, ANL/EAIS-2, Argonne National Laboratory, Argonne, Ill., July.

Whitfield, R.G., et al., 1994, "Health Risk Assessment of Ozone," in Tropospheric Ozone: Human Health and Agricultural Impacts, D.J. McKee, editor, Lewis Publishers, Inc., Boca Raton, Fla.

Whitfield, R.G., et al., 1996, A Probabilistic Assessment of Health Risks Associated with Short-Term Exposure to Tropospheric Ozone, ANL/DIS-3, Argonne National Laboratory, Argonne, Ill., July.

Whitfield, R.G., 1997a, A Probabilistic Assessment of Health Risks Associated with Short-Term Exposure to Tropospheric Ozone: A Supplement, letter report from Argonne National Laboratory, Argonne, Ill., to the U.S. Environmental Protection Agency, Office of Air Quality Planning and Standards, Research Triangle Park, N.C., Jan.

Whitfield, R.G., 1997b, Sensitivity of Health Risk Estimates to Air Quality Adjustment Procedure, letter report from Argonne National Laboratory, Argonne, Ill., to the U.S. Environmental Protection Agency, Office of Air Quality Planning and Standards, Research Triangle Park, N.C., June 30.

Winkler, R.L., et al., 1995, "The Risk of Chronic, Ozone-Induced Lung Injury," Operations Research 43:19-28. 


\section{APPENDIX A:}

\section{FORMATS OF PRINCIPAL CHRONIC INPUT AND OUTPUT FILES}

This appendix explains the formats of the principal input and output files

for chronic health endpoints.

The principal input files for both acute and chronic endpoints are exposure probability and exposure-response files. Each urban area, population, exposure time, and air quality scenario has one exposure file, and each health endpoint has one exposure-response file. The principal output files are headcount risk results files.

\section{A.1 HEADCOUNT RISK EXPOSURE PROBABILITY FILE FORMAT}

Table A.1 lists the exposure file for Los Angeles, children, exposure for one ozone season, and Scenario 1124P. Lines 1 and 5 are headers. Line 5 indicates that there are data for $10 \mathrm{pNEM} / \mathrm{O}_{3}$ runs. Lines 6-14 are exposure probabilities. Each line has one probability for each run that specifies the fraction (of children) who are exposed at the ozone concentration (actually, the interval for which the listed concentration is the midpoint) listed at the beginning of the line. For chronic endpoints, there are 9 exposure concentrations (parts per million [ppm] of ozone). For 8-hour exposures, there are 15 exposure concentrations. For 1-hour exposures (at both heavy and moderate exertion), there are 18 exposure concentrations. Two blank lines follow the exposure probabilities and separate two lines for total head count (TotalHC) and corrected head count (HC-Corr). In Table A.1, TotalHC is the number of children in Los Angeles; HC-Corr is the subset of children with personal exposure levels to ozone (i.e., seasonal mean daily maximum 8-hour average) greater or equal to background (0.025 ppm). The HC-Corr values usually differ from run to run. 
TABLE A.1 Exposure Probability File for Headcount Risk Endpoints: Los Angeles, Children, 8-hour Exposures, Scenario 1124P

\begin{tabular}{|c|c|c|c|c|c|c|c|c|c|c|c|}
\hline $\begin{array}{l}\text { Line } \\
\text { Number }\end{array}$ & \multicolumn{11}{|c|}{ Contents of Line } \\
\hline 1 & City = LA, & Population $=\mathrm{C}$ & \multicolumn{2}{|c|}{ Hours Exposed/Exceedance $=1124$, } & \multicolumn{2}{|c|}{ Measurement $=\mathrm{P}$} & & & & & \\
\hline 2 & & & & & & & & & & & \\
\hline \multicolumn{12}{|l|}{3} \\
\hline \multicolumn{12}{|l|}{4} \\
\hline 5 & PPM & Run 1 & Run 2 & Run 3 & Run 4 & Run 5 & Run 6 & Run 7 & Run 8 & Run 9 & Run 10 \\
\hline 6 & 0.029 & 0.022235 & 0.020713 & 0.021787 & 0.019427 & 0.019597 & 0.018373 & 0.017982 & 0.021691 & $\begin{array}{l}0.01941 \\
7\end{array}$ & $\begin{array}{l}0.01933 \\
0\end{array}$ \\
\hline 7 & 0.034 & 0.000000 & 0.000000 & 0.000000 & 0.000000 & 0.000000 & 0.000000 & 0.000000 & 0.000000 & $\begin{array}{l}0.00000 \\
0\end{array}$ & $\begin{array}{l}0.00000 \\
0\end{array}$ \\
\hline 8 & 0.038 & 0.000000 & 0.000000 & 0.000000 & 0.000000 & 0.000000 & 0.000000 & 0.000000 & 0.000000 & $\begin{array}{l}0.00000 \\
0\end{array}$ & $\begin{array}{l}0.00000 \\
0\end{array}$ \\
\hline 9 & 0.043 & 0.000000 & 0.000000 & 0.000000 & 0.000000 & 0.000000 & 0.000000 & 0.000000 & 0.000000 & $\begin{array}{l}0.00000 \\
0\end{array}$ & $\begin{array}{l}0.00000 \\
0\end{array}$ \\
\hline 10 & 0.049 & 0.000000 & 0.000000 & 0.000000 & 0.000000 & 0.000000 & 0.000000 & 0.000000 & 0.000000 & $\begin{array}{l}0.00000 \\
0\end{array}$ & $\begin{array}{l}0.00000 \\
0\end{array}$ \\
\hline 11 & 0.054 & 0.000000 & 0.000000 & 0.000000 & 0.000000 & 0.000000 & 0.000000 & 0.000000 & 0.000000 & $\begin{array}{l}0.00000 \\
0\end{array}$ & $\begin{array}{l}0.00000 \\
0\end{array}$ \\
\hline 12 & 0.058 & 0.000000 & 0.000000 & 0.000000 & 0.000000 & 0.000000 & 0.000000 & 0.000000 & 0.000000 & $\begin{array}{l}0.00000 \\
0\end{array}$ & $\begin{array}{l}0.00000 \\
0\end{array}$ \\
\hline 13 & 0.064 & 0.000000 & 0.000000 & 0.000000 & 0.000000 & 0.000000 & 0.000000 & 0.000000 & 0.000000 & $\begin{array}{l}0.00000 \\
0\end{array}$ & $\begin{array}{l}0.00000 \\
0\end{array}$ \\
\hline 14 & 0.068 & 0.000000 & 0.000000 & 0.000000 & 0.000000 & 0.000000 & 0.000000 & 0.000000 & 0.000000 & $\begin{array}{l}0.00000 \\
0\end{array}$ & $\begin{array}{l}0.00000 \\
0\end{array}$ \\
\hline \multicolumn{12}{|l|}{15} \\
\hline \multicolumn{12}{|l|}{16} \\
\hline 17 & TotalHC & 798290 & 798290 & 798290 & 798290 & 798290 & 798290 & 798290 & 798290 & 798290 & 798290 \\
\hline 18 & HC-Corr & 17750 & 16535 & 17392 & 15508 & 15644 & 14667 & 14355 & 17316 & 15500 & 15431 \\
\hline
\end{tabular}




\section{A.2 HEADCOUNT RISK EXPOSURE RESPONSE FILE FORMAT}

Table A.2 is an example of a chronic exposure-response file (Expert A, mild lesions, Los Angeles and New York, children and workers, one ozone season). The first six lines give header information. The next 21 lines specify the fractional response rate for specific exposure concentrations and fractiles. For example, the median response $[\mathrm{R}(11)]$ is listed in line 17 , the 0.01 -fractile response $[R(1)]$ is listed in line 7 , and the 0.99 -fractile response $[\mathrm{R}(21)]$ is listed in line 27 . The first numerical entry is the response rate at background, which is $0.025 \mathrm{ppm}$ of ozone.

\section{A.3 HEADCOUNT RISK RESULTS FILE FORMAT}

While the exposure probability and exposure-response files vary in size for acute endpoints, the format for risk results files is the same for all health endpoints and exposure durations. The output file (see Table A.3) consists of three sections. The top section (lines 1-12) contains information about the exposure and exposure-response files used to calculate results. The middle section (lines 13-37) lists the fractional response rates with no correction for background. The bottom section (lines 41-65) lists the number of children responding after correction for background ozone. Because of space limitations, the table contains results only for runs $1-6$. Below the data for the probability distribution for each run are the mean, standard deviation, and number of people (children) associated with the $\mathrm{pNEM} / \mathrm{O}_{3}$ run (lines 35-37 for uncorrected results, lines 63-65 for corrected results). Note that the uncorrected results are about ten times higher than the results corrected for background. 
TABLE A.2 Exposure-Response Relationship File for a Chronic Health Endpoint: Expert A, Mild Lesions, Los Angeles and New York City, Children and Workers, One Ozone Season

\begin{tabular}{|c|c|c|c|c|c|c|c|c|c|c|c|}
\hline $\begin{array}{c}\text { Line } \\
\text { Number }\end{array}$ & \multicolumn{11}{|c|}{ Contents of Line } \\
\hline 1 & \multirow{3}{*}{$\begin{array}{c}\text { Ozone } \\
\text { frac }\end{array}$} & ert A, Mild, L & $=\mathrm{NY}, \mathrm{C}=\mathrm{W}$, & Season (Source: & : AIBB1.RAW & ) & & & & & \\
\hline 2 & & concentratio & (ppm) & & & & & & & & \\
\hline 3 & & & & & & & & & 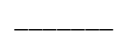 & & \\
\hline 4 & & & & & & & & & & & \\
\hline 5 & & 0.025 & 0.028 & 0.033 & 0.038 & 0.043 & 0.048 & 0.053 & 0.058 & 0.063 & 0.068 \\
\hline 6 & & & & & & & & & & & \\
\hline 7 & 0.01 & 0.010000 & 0.013600 & 0.019600 & 0.025600 & 0.031600 & 0.037600 & 0.053200 & 0.075200 & 0.097200 & 0.119200 \\
\hline 8 & 0.05 & 0.014706 & 0.019875 & 0.028489 & 0.037103 & 0.045718 & 0.054332 & 0.071668 & 0.094818 & 0.117969 & 0.141119 \\
\hline 9 & 0.10 & 0.020588 & 0.027718 & 0.039600 & 0.051482 & 0.063365 & 0.075247 & 0.094753 & 0.119341 & 0.143929 & 0.168518 \\
\hline 10 & 0.15 & 0.026471 & 0.035105 & 0.049495 & 0.063885 & 0.078275 & 0.092665 & 0.114493 & 0.141279 & 0.168066 & 0.194852 \\
\hline 11 & 0.20 & 0.032353 & 0.042492 & 0.059389 & 0.076287 & 0.093185 & 0.110083 & 0.134233 & 0.163217 & 0.192202 & 0.221186 \\
\hline 12 & 0.25 & 0.038235 & 0.049879 & 0.069284 & 0.088690 & 0.108095 & 0.127501 & 0.153973 & 0.185155 & 0.216338 & 0.247521 \\
\hline 13 & 0.30 & 0.044118 & 0.057395 & 0.079524 & 0.101653 & 0.123782 & 0.145910 & 0.174661 & 0.207826 & 0.240992 & 0.274157 \\
\hline 14 & 0.35 & 0.050000 & 0.065429 & 0.091143 & 0.116857 & 0.142571 & 0.168286 & 0.199143 & 0.233429 & 0.267714 & 0.302000 \\
\hline 15 & 0.40 & 0.066667 & 0.082952 & 0.110095 & 0.137238 & 0.164381 & 0.191524 & 0.222095 & 0.254952 & 0.287810 & 0.320667 \\
\hline 16 & 0.45 & 0.083333 & 0.100476 & 0.129048 & 0.157619 & 0.186190 & 0.214762 & 0.245048 & 0.276476 & 0.307905 & 0.339333 \\
\hline 17 & 0.50 & 0.100000 & 0.118000 & 0.148000 & 0.178000 & 0.208000 & 0.238000 & 0.268000 & 0.298000 & 0.328000 & 0.358000 \\
\hline 18 & 0.55 & 0.126316 & 0.146577 & 0.180346 & 0.214115 & 0.247885 & 0.281654 & 0.311075 & 0.337599 & 0.364122 & 0.390645 \\
\hline 19 & 0.60 & 0.152632 & 0.175154 & 0.212693 & 0.250231 & 0.287769 & 0.325307 & 0.354151 & 0.377197 & 0.400244 & 0.423290 \\
\hline 20 & 0.65 & 0.178947 & 0.203732 & 0.245039 & 0.286346 & 0.327654 & 0.368961 & 0.397226 & 0.416796 & 0.436366 & 0.455935 \\
\hline 21 & 0.70 & 0.211111 & 0.237455 & 0.281362 & 0.325269 & 0.369176 & 0.413082 & 0.440301 & 0.456394 & 0.472487 & 0.488581 \\
\hline 22 & 0.75 & 0.266667 & 0.291763 & 0.333591 & 0.375419 & 0.417247 & 0.459075 & 0.483376 & 0.495993 & 0.508609 & 0.521226 \\
\hline 23 & 0.80 & 0.328571 & 0.351659 & 0.390138 & 0.428618 & 0.467097 & 0.505576 & 0.526452 & 0.535591 & 0.544731 & 0.553871 \\
\hline 24 & 0.85 & 0.400000 & 0.418800 & 0.450133 & 0.481467 & 0.512800 & 0.544133 & 0.561200 & 0.568756 & 0.576311 & 0.583867 \\
\hline 25 & 0.90 & 0.435714 & 0.454229 & 0.485086 & 0.515943 & 0.546800 & 0.577657 & 0.593867 & 0.600311 & 0.606756 & 0.613200 \\
\hline 26 & 0.95 & 0.471429 & 0.489657 & 0.520038 & 0.550419 & 0.580800 & 0.611181 & 0.626533 & 0.631867 & 0.637200 & 0.642533 \\
\hline 27 & 0.99 & 0.500000 & 0.518000 & 0.548000 & 0.578000 & 0.608000 & 0.638000 & 0.653600 & 0.659600 & 0.665600 & 0.671600 \\
\hline
\end{tabular}


TABLE A.3 Risk Results File for a Chronic Health Endpoint: Expert A, Mild Lesions, Los Angeles, Children, One Ozone Season, Scenario 1124P

\begin{tabular}{|c|c|c|c|c|c|c|c|}
\hline $\begin{array}{l}\text { Line } \\
\text { Number }\end{array}$ & \multicolumn{7}{|c|}{ Contents of Line } \\
\hline 1 & & & & & & & \\
\hline 2 & \multicolumn{7}{|c|}{ 09-08-1997 15:18:15 } \\
\hline 3 & & & & & & & \\
\hline 4 & \multicolumn{7}{|c|}{ AILCO.ERF } \\
\hline 5 & \multicolumn{7}{|c|}{ Health File: Expert: A, Lesion: Mild, City\$: L, Population: C, Seasons: 10} \\
\hline 6 & & & & & & & \\
\hline 7 & \multicolumn{7}{|c|}{ LAC1124P.SP } \\
\hline 8 & \multicolumn{7}{|c|}{$\begin{array}{l}\text { Exposure File: City }=\text { LA, Population }=\mathrm{C} \text {, Hours Exposed } / \text { Exceedance }=1124 \text {, Measurement } \\
=\mathrm{P}\end{array}$} \\
\hline \multicolumn{8}{|c|}{ ( } \\
\hline \multicolumn{8}{|l|}{10} \\
\hline \multicolumn{8}{|l|}{11} \\
\hline 12 & FRAC & RUN 1 & RUN 2 & RUN 3 & RUN 4 & RUN 5 & RUN 6 \\
\hline 13 & 0.01 & 0.000302 & 0.000282 & 0.000296 & 0.000264 & 0.000267 & 0.000250 \\
\hline 14 & 0.05 & 0.000442 & 0.000412 & 0.000433 & 0.000386 & 0.000389 & 0.000365 \\
\hline 15 & 0.10 & 0.000616 & 0.000574 & 0.000604 & 0.000538 & 0.000543 & 0.000509 \\
\hline 16 & 0.15 & 0.000781 & 0.000727 & 0.000765 & 0.000682 & 0.000688 & 0.000645 \\
\hline 17 & 0.20 & 0.000945 & 0.000880 & 0.000926 & 0.000825 & 0.000833 & 0.000781 \\
\hline 18 & 0.25 & 0.001109 & 0.001033 & 0.001087 & 0.000969 & 0.000977 & 0.000916 \\
\hline 19 & 0.30 & 0.001276 & 0.001189 & 0.001250 & 0.001115 & 0.001125 & 0.001055 \\
\hline 20 & 0.35 & 0.001455 & 0.001355 & 0.001426 & 0.001271 & 0.001282 & 0.001202 \\
\hline 21 & 0.40 & 0.001844 & 0.001718 & 0.001807 & 0.001612 & 0.001626 & 0.001524 \\
\hline 22 & 0.45 & 0.002234 & 0.002081 & 0.002189 & 0.001952 & 0.001969 & 0.001846 \\
\hline 23 & 0.50 & 0.002624 & 0.002444 & 0.002571 & 0.002292 & 0.002312 & 0.002168 \\
\hline 24 & 0.55 & 0.003259 & 0.003036 & 0.003193 & 0.002848 & 0.002872 & 0.002693 \\
\hline 25 & 0.60 & 0.003895 & 0.003628 & 0.003816 & 0.003403 & 0.003432 & 0.003218 \\
\hline 26 & 0.65 & 0.004530 & 0.004220 & 0.004439 & 0.003958 & 0.003993 & 0.003743 \\
\hline 27 & 0.70 & 0.005280 & 0.004918 & 0.005173 & 0.004613 & 0.004653 & 0.004363 \\
\hline 28 & 0.75 & 0.006487 & 0.006043 & 0.006357 & 0.005668 & 0.005718 & 0.005361 \\
\hline 29 & 0.80 & 0.007819 & 0.007284 & 0.007662 & 0.006832 & 0.006891 & 0.006461 \\
\hline 30 & 0.85 & 0.009312 & 0.008675 & 0.009124 & 0.008136 & 0.008207 & 0.007695 \\
\hline 31 & 0.90 & 0.010100 & 0.009408 & 0.009896 & 0.008824 & 0.008902 & 0.008346 \\
\hline 32 & 0.95 & 0.010888 & 0.010142 & 0.010668 & 0.009513 & 0.009596 & 0.008996 \\
\hline 33 & 0.99 & 0.011518 & 0.010729 & 0.011286 & 0.010063 & 0.010151 & 0.009517 \\
\hline
\end{tabular}


TABLE A.3 (Cont.)

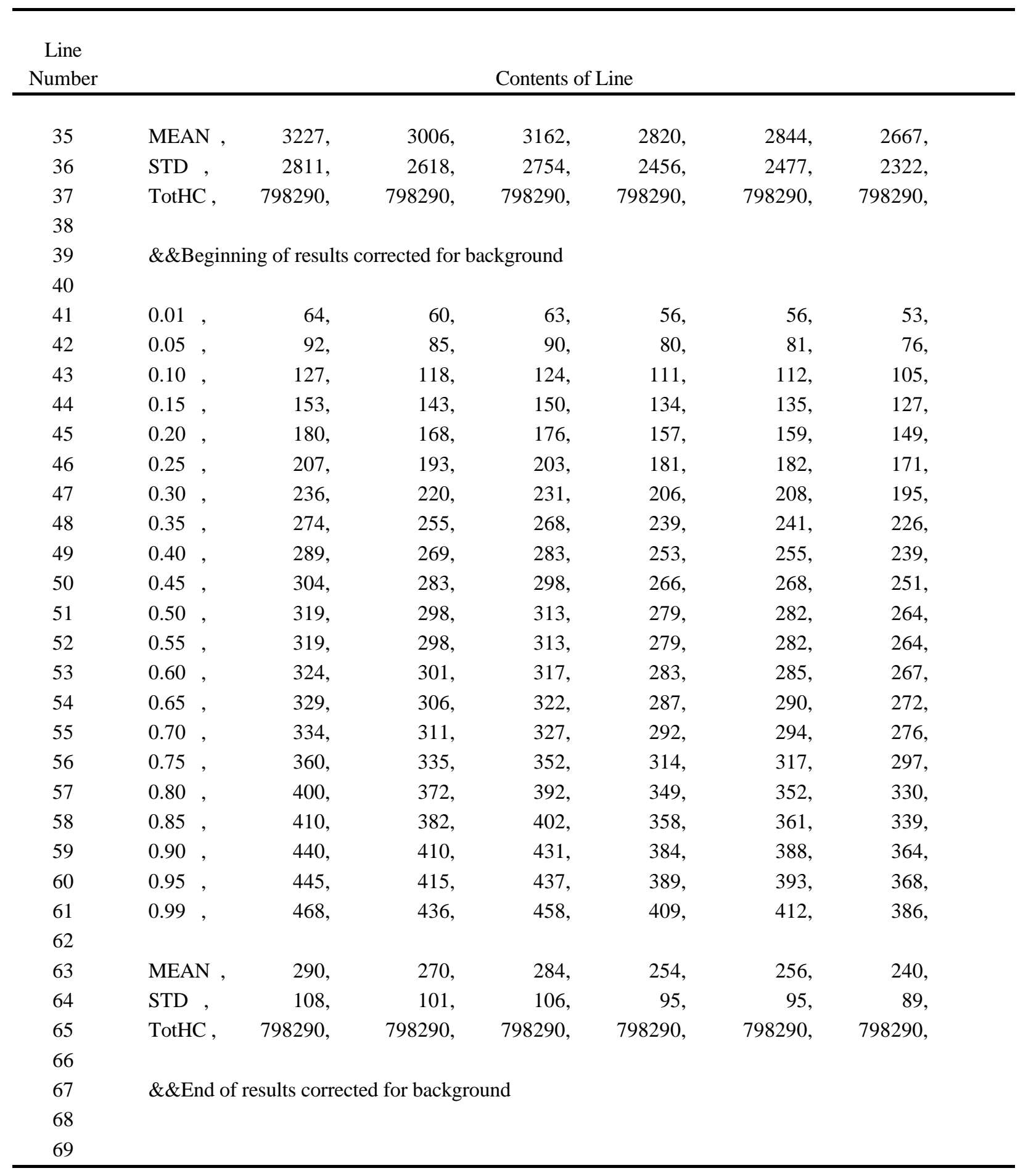




\section{APPENDIX B:}

\section{INFORMATION ABOUT HEALTH ENDPOINTS AND AIR QUALITY SCENARIOS USED IN ORAMUS}

The table in this appendix provides additional information about the air quality scenarios used in the Ozone Risk AssessMent UtilitieS (ORAMUS) software system. Table B.1 lists the air quality scenarios available for the Los Angeles and New York City urban areas for chronic health endpoints. 
TABLE B.1 Air Quality Scenarios Available for Chronic Risk Assessments (formation of centriacinar lesions; persons)

\begin{tabular}{|c|c|c|c|}
\hline \multicolumn{2}{|c|}{ Air Quality Scenario } & \multicolumn{2}{|c|}{ Urban Area } \\
\hline Name & Abbreviation & Los Angeles & New York City \\
\hline As-Is & $\mathrm{Z}=\mathrm{ASIS}$ & $\mathrm{C}, \mathrm{W}^{\mathrm{a}}$ & $\mathrm{C}, \mathrm{W}$ \\
\hline 8H1EX-0.10 & $\mathrm{D}=8110$ & $\mathrm{C}, \mathrm{W}$ & $\mathrm{C}, \mathrm{W}$ \\
\hline 1H1EX-0.12 & $\mathrm{A}=1112$ & $\mathrm{C}, \mathrm{W}$ & $\mathrm{C}, \mathrm{W}$ \\
\hline 8H1EX-0.09 & $B=8109$ & $\mathrm{C}, \mathrm{W}$ & $\mathrm{C}, \mathrm{W}$ \\
\hline 8H5EX-0.08 & $F=8508$ & $\mathrm{C}, \mathrm{W}$ & $\mathrm{C}, \mathrm{W}$ \\
\hline 1H1EX-0.10 & $\mathrm{H}=1110$ & $\mathrm{C}, \mathrm{W}$ & $\mathrm{C}, \mathrm{W}$ \\
\hline 8H5EX-0.09 & $\mathrm{J}=8509$ & $\mathrm{C}, \mathrm{W}$ & $\mathrm{C}, \mathrm{W}$ \\
\hline 8H1EX-0.08 & $\mathrm{C}=8108$ & $\mathrm{C}, \mathrm{W}$ & $\mathrm{C}, \mathrm{W}$ \\
\hline 8H1EX-0.07 & $\mathrm{G}=8107$ & $\mathrm{C}, \mathrm{W}$ & $\mathrm{C}, \mathrm{W}$ \\
\hline 1H1EX-0.124 & $\mathrm{S}=1124 \mathrm{P}^{\mathrm{b}}$ & $\mathrm{C}$ & $\mathrm{C}$ \\
\hline 1H1EX-0.124, Weibull & $\mathrm{U}=1124 \mathrm{~W}^{\mathrm{b}}$ & $\mathrm{C}$ & $\mathrm{C}$ \\
\hline 1H1EX-0.124, Quadratic & $Y=1124 Q^{b}$ & $\mathrm{C}$ & $\mathrm{C}$ \\
\hline 8НA3H-0.094 & $\mathrm{R}=8394 \mathrm{P}$ & $\mathrm{C}$ & $\mathrm{C}$ \\
\hline 8HA3H-0.094, Weibull & $(=8394 \mathrm{~W}$ & $\mathrm{C}$ & $\mathrm{C}$ \\
\hline 8HA3H-0.094, Quadratic & ) $=8394 \mathrm{Q}$ & $\mathrm{C}$ & $\mathrm{C}$ \\
\hline 8HA2H-0.094 & $Q=8294$ & $\mathrm{C}$ & $\mathrm{C}$ \\
\hline 8HA7H-0.084 & $\mathrm{T}=8784 \mathrm{P}$ & $\mathrm{C}$ & $\mathrm{C}$ \\
\hline 8HA7H-0.084, Weibull & $\mathrm{V}=8784 \mathrm{~W}$ & $\mathrm{C}$ & $\mathrm{C}$ \\
\hline 8HA7H-0.084, Quadratic & $\mathrm{I}=8784 \mathrm{Q}$ & $\mathrm{C}$ & $\mathrm{C}$ \\
\hline 8НA5H-0.084 & $\mathrm{N}=8584 \mathrm{P}$ & $\mathrm{C}$ & $\mathrm{C}$ \\
\hline 8HA5H-0.084, Weibull & $\mathrm{W}=8584 \mathrm{~W}$ & $\mathrm{C}$ & $\mathrm{C}$ \\
\hline 8HA5H-0.084, Quadratic & $\mathrm{K}=8584 \mathrm{Q}$ & $\mathrm{C}$ & $\mathrm{C}$ \\
\hline 8НA3H-0.084 & $\mathrm{O}=8384 \mathrm{P}$ & $\mathrm{C}$ & $\mathrm{C}$ \\
\hline 8HA3H-0.084, Weibull & $\mathrm{X}=8384 \mathrm{~W}$ & $\mathrm{C}$ & $\mathrm{C}$ \\
\hline 8HA3H-0.084, Quadratic & $\mathrm{L}=8384 \mathrm{Q}$ & $\mathrm{C}$ & $\mathrm{C}$ \\
\hline 8НA2H-0.084 & $\mathrm{M}=8284$ & $\mathrm{C}$ & $\mathrm{C}$ \\
\hline 8НА3Н-0.080 & $\mathrm{P}=8380$ & $\mathrm{C}$ & $\mathrm{C}$ \\
\hline
\end{tabular}

a $\mathrm{C}$ denotes outdoor children; $\mathrm{W}$ denotes outdoor workers.

b The fifth character denotes the air quality adjustment procedure: $\mathrm{P}$ denotes proportional; $\mathrm{W}$ denotes Weibull; and $\mathrm{Q}$ denotes quadratic; no fifth character indicates that a proportional adjustment procedure was used. 